\title{
The importance of terrestrial weathering changes in multimillennial recovery of the global carbon cycle: a two-dimensional perspective
}

\author{
Marc-Olivier Brault ${ }^{1}$, H. Damon Matthews ${ }^{2}$, and Lawrence A. Mysak ${ }^{3}$ \\ ${ }^{1}$ Department of Geography, McGill University, Montréal, Canada \\ ${ }^{2}$ Department of Geography, Planning and Environment, Concordia University, Montréal, Canada \\ ${ }^{3}$ Department of Atmospheric and Oceanic Sciences, McGill University, Montréal, Canada \\ Correspondence to: Marc-Olivier Brault (marc-olivier.brault@mail.mcgill.ca) \\ Received: 31 October 2016 - Discussion started: 2 January 2017 \\ Revised: 8 April 2017 - Accepted: 11 April 2017 - Published: 30 June 2017
}

\begin{abstract}
In this paper, we describe the development and application of a new spatially explicit weathering scheme within the University of Victoria Earth System Climate Model (UVic ESCM). We integrated a dataset of modern-day lithology with a number of previously devised parameterizations for weathering dependency on temperature, primary productivity, and runoff. We tested the model with simulations of future carbon cycle perturbations, comparing a number of emission scenarios and model versions with each other and with zero-dimensional equivalents of each experiment. Overall, we found that our two-dimensional weathering model versions were more efficient in restoring the carbon cycle to its pre-industrial state following the pulse emissions than their zero-dimensional counterparts; however, in either case the effect of this weathering negative feedback on the global carbon cycle was small on timescales of less than 1000 years. According to model results, the largest contribution to future changes in weathering rates came from the expansion of tropical and mid-latitude vegetation in grid cells dominated by weathering-vulnerable rock types, whereas changes in temperature and river runoff had a more modest direct effect. Our results also confirmed that silicate weathering is the only mechanism that can lead to a full recovery of the carbon cycle to pre-industrial levels on multimillennial timescales.
\end{abstract}

\section{Introduction}

\subsection{Rationale}

The weathering of carbonate and silicate rocks on land is a key process in the global carbon cycle and, through its coupling with calcium carbonate deposition in the ocean, is the primary sink of carbon on geologic timescales (Urey, 1952; Walker et al., 1981). The rate at which these processes remove carbon from the Earth system is sensitive to changes in the environment, notably temperature (Berner, 1991), biological productivity (Lenton and Britton, 2006), and, perhaps more indirectly, river runoff (Walker and Kasting, 1992). This gives rise to a negative feedback mechanism which regulates the global climate on multimillennial timescales. How- ever, its relevance over time frames of $10^{4}$ years or shorter has of yet been left mostly unexplored.

Here, we introduce a new model of rock weathering developed for use within the University of Victoria Earth System Climate Model (UVic ESCM); this model incorporates a spatially explicit interactive computation of weathering rates to close the global carbon cycle on multimillennial timescales. The model is based on a lithology-dependent calculation of steady-state weathering fluxes, which are modulated by transient changes in environmental conditions akin to the 0-D carbon cycle models already present in the literature (e.g., Meissner et al., 2012). We tested the model with simulations of future climate changes following anthropogenic carbon emissions, comparing the output to that of earlier weathering models, both 2-D (Colbourn et al., 2013) and 0-D (Lenton and Britton, 2006). 


\subsection{The rock weathering cycle}

The chemical weathering of rocks is characterized by the cleavage of bonds of the mineral lattice by water, often in the presence of a secondary weathering agent - hydronium or $\mathrm{OH}$ ions, low-molecular-weight organic chelators, or carbonic acid $\left(\mathrm{H}_{2} \mathrm{CO}_{3}\right.$; a product of carbon dioxide dissolution in rainwater). Rock weathering products, including calcium and bicarbonate ions (respectively the most abundant cation and anion in most river waters), can be carried away with runoff to rivers and into the ocean. For example, calcium carbonate dissolution by carbonic acid is given by (Archer et al., 1997)

$\mathrm{CaCO}_{3}+\mathrm{CO}_{2}+\mathrm{H}_{2} \mathrm{O} \rightarrow \mathrm{Ca}^{2+}+2 \mathrm{HCO}_{3}^{-}$.

The influx of dissolved inorganic carbon (henceforth DIC) and alkalinity to the ocean surface layer is balanced by the precipitation and burial of biogenic calcium carbonate $\left(\mathrm{CaCO}_{3}\right)$ in the marine sediments, and ocean alkalinity is a key factor in determining the carbonate compensation depth (CCD), the depth below which the dissolution rate of calcium carbonate exceeds its precipitation rate. In the long term this allows the ocean to maintain a remarkably stable alkalinity, as any increases in ocean acidity (such as can be caused by a $\mathrm{CO}_{2}$ invasion from the atmosphere) can be neutralized by elevating the $\mathrm{CCD}$, which dissolves carbonate sediments and releases carbonate ions $\left(\mathrm{CO}_{3}^{2-}\right)$ back into the ocean. This oceanic buffer factor, along with carbonate dissolution on land (due to weathering), is the primary means through which ocean alkalinity is restored, and it is responsible for maintaining both atmospheric and oceanic $p \mathrm{CO}_{2}$ close to equilibrium. In short, the weathering of calcium carbonate can accelerate the transfer of $\mathrm{CO}_{2}$ between the atmosphere and ocean, but it does not contribute to a permanent return of carbon to the geologic reservoir (Ridgwell and Zeebe, 2005; Sarmiento and Gruber, 2006).

A certain fraction of rock weathering reactions involve a weakening of chemical bonds in the mineral lattice on contact with water whereby hydrogen ions replace positively charged cations (mostly $\mathrm{Ca}^{2+}$ and $\mathrm{Mg}^{2+}$ ) which are bounded to negatively charged ions, most particularly $\mathrm{SiO}_{4}$ (silicate) structures. One of the most common examples is given by calcium silicate hydrolysis, as described by the following schematic reaction (Ebelmen, 1845; Urey, 1952):

$\mathrm{CaSiO}_{3}+2 \mathrm{CO}_{2}+3 \mathrm{H}_{2} \mathrm{O} \rightarrow \mathrm{Ca}^{2+}+\mathrm{H}_{4} \mathrm{SiO}_{4}+2 \mathrm{HCO}_{3}^{-}$.

This equation represents the weathering of any silicate mineral into silicic acid (which often precipitates as amorphous silica $\mathrm{SiO}_{2}$ ), and it consumes one more molecule of $\mathrm{CO}_{2}$ than carbonate dissolution while sending the same amounts of calcium and bicarbonate ions to the ocean. The combination of Eq. (2) with calcium carbonate precipitation (the reverse of Eq. 1) shows how this results in a net removal of one molecule of $\mathrm{CO}_{2}$ :

$\mathrm{CaSiO}_{3}+\mathrm{CO}_{2} \rightarrow \mathrm{CaCO}_{3}+\mathrm{SiO}_{2}$.
Weathering rates due to silicate hydrolysis tend to be considerably slower than from the dissolution of carbonate minerals - it removes on average 0.28 to $0.30 \mathrm{PgC}$ per year (Amiotte Suchet and Probst, 1995) - hence the effect of atmospheric $\mathrm{CO}_{2}$ consumption by silicate weathering only becomes a significant sink of carbon on geologic timescales $\left(10^{5}-10^{6}+\right.$ years $)$. For the remainder of this article, dissolution of carbonates (on land) and hydrolysis of silicates will be treated separately and referred to as carbonate and silicate weathering, respectively.

\subsection{A brief history of weathering in global carbon cycle models}

Variations in rock weathering rates have long been believed to hold a major role in regulating the Earth's long-term climate, and early (non-spatially explicit) carbon cycle models were built to investigate the importance of the weathering feedback mechanism on various events in Earth's geological history. Walker et al. (1981) developed expressions relating silicate weathering rates to atmospheric $p \mathrm{CO}_{2}$ (indirectly through vegetation productivity) and temperature (including a weak dependency on runoff) and used them to offer a solution to the faint young Sun paradox by providing a convenient mechanism for a slow and steady decrease in atmospheric greenhouse gas concentrations. Berner et al. (1983) also linked the rate of atmospheric $\mathrm{CO}_{2}$ consumption by silicate weathering to changes in surface air temperature, atmospheric partial $\mathrm{CO}_{2}$ pressure, and river runoff and offered this dependency as a possible explanation for the general decreasing trend of atmospheric $\mathrm{CO}_{2}$ levels on geologic timescales. Although these models used rudimentary parameterizations derived from early general circulation models (GCMs) and experimental data, they built a foundation for future longterm carbon cycle model studies.

Following Berner et al. (1983), Berner (1991) built a geochemical cycle model, now called GEOCARB, in which the long-term evolution of atmospheric carbon content would be driven by imbalances between $\mathrm{CO}_{2}$ outgassing by volcanic activity and the burial of carbonate sediments following the weathering of silicate rocks. The latter was given a dependency on air temperature and atmospheric $\mathrm{CO}_{2}$, and it was used to solve a series of mass balance equations in order to determine the inward and outward fluxes for the atmosphereocean, land, and mineralogical carbon reservoirs. Subsequent versions were called GEOCARB II (Berner, 1994) and GEOCARB III (Berner and Kothavala, 2001), and these further improved the weathering parameterizations based on the latest observational data and GCM output. They were later coupled with a model of atmospheric $\mathrm{O}_{2}$ and ocean nutrients to create COPSE (Bergman et al., 2004), a multi-element geochemical cycling model which introduces a feedbackbased interaction between biotic and abiotic elements of the Earth system. Most recent work on this matter (Ridgwell and Hargreaves, 2007; Montenegro et al., 2007; Uchikawa and 
Zeebe, 2008; Archer et al., 2009; Eby et al., 2009) has involved intermediate-complexity models, which are usually limited in scope to $10^{4}$ years or shorter. Hence, the weathering feedback mechanism in these studies is limited to the $\mathrm{pH}$ neutralization effect of carbonate weathering on the oceans (which restores the lysocline to its original depth), and silicate weathering is either ignored altogether or prescribed as a global constant average flux.

In a pioneering study, Walker and Kasting (1992) considered the impact of the rock cycle and carbonate sediment dissolution in projections of future changes in the global carbon cycle. Their model was built on the assumption that the dependency of carbonate and silicate weathering rates to changes in the carbon cycle (i.e., atmospheric $\mathrm{CO}_{2}$ levels) was purely abiotic, which was in line with the other geochemical cycling models of the time. Following on Walker and Kasting (1992) as well as the recent innovations in COPSE, Lenton and Britton (2006) posited that biological changes in the Earth system could further enhance the increase or decrease in rock weathering rates, especially in the context of a rapidly warming world which would likely result from unabated anthropogenic emissions. Their carbon cycle model included sophisticated biotic and abiotic transports of carbon, introducing a box-model representation of carbonate and silicate weathering processes in which weathering rates were directly dependent on plant productivity, rather than on atmospheric $\mathrm{CO}_{2}$ concentrations. This allowed them to investigate the role of land use changes on the longterm recovery of atmospheric $\mathrm{CO}_{2}$; in particular, they found that vegetation-suppressing land use changes would force $\mathrm{CO}_{2}$ levels to stabilize above pre-industrial levels on geologic timescales, thus indefinitely trapping some of the anthropogenic emissions in the atmosphere.

\subsection{On spatially explicit weathering models}

Few attempts have been made to explore the spatial variability of carbonate and silicate weathering rates and how it may affect the global efficacy of the weathering negative feedback mechanism. The GEM-CO 2 model (Amiotte Suchet and Probst, 1995) defined spatial variability in terms of rock types, using data for bicarbonate $\left(\mathrm{HCO}_{3}^{-}\right)$concentration and runoff collected over various mono-lithologic drainage basins (Meybeck, 1987) to establish empirical linear relationships between weathering flux and runoff for a series of major rock types, and calculated the global distribution of $\mathrm{CO}_{2}$ consumption by weathering based on the spatial heterogeneity of those two factors alone. Their results showed a higher intensity of weathering in the Northern Hemisphere (due to rock type) and in equatorial regions (due to runoff). They later refined the global distribution of rock types by attributing one of six rock types to each land unit of a $1^{\circ} \times 1^{\circ}$ grid (Amiotte Suchet et al., 2003); this distribution will be used as the basis for our spatially explicit weathering scheme. Using the GEM- $\mathrm{CO}_{2}$ model, carbonate rocks and shales were found to both consume $40 \%$ of the total continental $\mathrm{CO}_{2}$ uptake despite occupying a much smaller fraction of land area, while sandstones and shield rocks contributed much lower than their outcrop abundance. A similar rock type distribution was developed (Gibbs and Kump, 1994; Bluth and Kump, 1994) (henceforth GKWM), using both an empirical linear coefficient and an exponential factor to express weathering dependence on runoff for different rock types; the results produced by their lithological distribution were found to be very similar to that of GEM-CO ${ }_{2}$, in terms of global weathering intensity and the consumption of atmospheric/soil $\mathrm{CO}_{2}$.

Other instances of spatially explicit weathering models include the GEOCLIM model (Donnadieu et al., 2009), which uses 3-D GCM results to prescribe changes in weathering rates and investigate their impacts on a box-model ocean. It has been used to investigate the climatic impacts of tectonic continental reorganization and weathering-vegetation interactions. More recently, a spatially explicit scheme was added to the GENIE model (Colbourn et al., 2013), using lithological databases from the GEM-CO ${ }_{2}$ and GKWM models, temperature dependency from the GEOCARB models, net primary productivity (NPP) dependency as introduced by Lenton and Britton (2006), and runoff dependency from GEM-CO ${ }_{2}$. Although the paper focused mostly on exploring the various model options, the authors were able to simulate the entirety of the climate system recovery from a $5000 \mathrm{Pg} \mathrm{C}$ anthropogenic pulse at year 2000, showing that within $0.5-1 \mathrm{Myr}$ the atmospheric $\mathrm{CO}_{2}$ levels would return to pre-industrial levels.

\section{Methods}

\subsection{Climate model description}

In this study we used version 2.9 of the University of Victoria Earth System Climate Model (henceforth UVic ESCM, or UVic model), which is an intermediate-complexity coupled atmosphere-ocean-sea-ice model with integrated land surface and vegetation schemes (Weaver et al., 2001). Its main component is version 2.2 of the GFDL Modular Ocean Model (MOM), a three-dimensional ocean GCM with 19 uneven vertical levels (Pacanowski, 1995), which is coupled to a vertically integrated energy-moisture balance atmosphere model (Fanning and Weaver, 1996), a dynamicthermodynamic sea-ice model (Bitz et al., 2001), a land surface scheme and dynamic global vegetation model (Meissner et al., 2003), and a sedimentation model (Archer, 1996). Land surface properties (surface temperature, soil moisture content and temperature, and snow cover) and soil carbon content are computed with a single $(1 \mathrm{~m})$ layer version of the Meteorological Office Surface Exchange Scheme version 2 (MOSES-2) (Cox et al., 1999), and terrestrial vegetation dynamics are handled by the Hadley Centre's Top-down Representation of Interactive Foliage and Flora Including Dy- 
namics (TRIFFID) model (Cox, 2001). TRIFFID describes the state of the terrestrial biosphere in terms of soil carbon content and vegetation distribution, which is expressed through the structure and coverage of five plant functional types: broadleaf tree, needleleaf tree, $\mathrm{C}_{3}$ grass, $\mathrm{C}_{4}$ grass, and shrub vegetation.

The UVic ESCM also includes a fully coupled global carbon cycle, which consists of inorganic carbon chemistry and air-sea exchange of $\mathrm{CO}_{2}$ (Ewen et al., 2004), and a nutrientphytoplankton-zooplankton-detritus (NPZD) module which calculates the contribution of the biological pump to ocean biogeochemistry (Schartau and Oshlies, 2003; Schmittner et al., 2008). Terrestrial carbon fluxes and reservoirs are described by Matthews et al. (2005) and coupled to the global model by Meissner et al. (2003).

The model is driven in the short term by seasonal variations in solar insolation and wind fields (Kalnay et al., 1996), and in the long term by orbital parameter changes and a reconstruction of atmospheric $\mathrm{CO}_{2}$ content over the past 20000 years (Indermühle et al., 1999). The spatial coverage and height of continental ice sheets is prescribed every 1000 years using data from the model ICE-5G (Peltier, 2004); thus these ice sheet configurations also serve to drive climate changes during glacial periods. The land-sea configuration used in all sub-components operates in a global spatial domain with a spherical grid resolution of $3.6^{\circ}$ (zonal) by $1.8^{\circ}$ (meridional), which is comparable to most coupled coarse-resolution atmosphere-ocean GCMs.

\subsection{Weathering model description}

Terrestrial weathering in the UVic model is parameterized as a land-to-ocean flux of dissolved inorganic carbon $\left(F_{\mathrm{DIC}}\right)$ and alkalinity $\left(F_{\mathrm{ALK}}\right.$, with $\left.F_{\mathrm{ALK}}=2 F_{\mathrm{DIC}}\right)$ via river discharge. In the standard version of the model, the incoming flux of carbon to the ocean as weathering is set to equal the net burial rate of $\mathrm{CaCO}_{3}$ in order to balance the long-term carbon and alkalinity budgets in the ocean; the initial, steadystate value is typically held constant throughout the transient model runs. This effectively suppresses the long-term negative feedback mechanism by preventing the weathering rate from adapting to changes in environmental factors such as temperature and atmospheric $\mathrm{CO}_{2}$ concentration. Meissner et al. (2012) replaced the standard parameterization of weathering in the UVic model with a number of adaptations from previous carbon cycle box models in order to investigate the role of rock weathering as a carbon sink for anthropogenic carbon emissions. They found that the long-term climate response to various emission scenarios depends almost exclusively on the total amount of $\mathrm{CO}_{2}$ released regardless of the rate at which it is being emitted, and carbon uptake through an increase in terrestrial weathering has a significant effect on the climate system. There were, however, some differences between the various weathering schemes concerning the rate of carbon removal.
In this section we describe a spatially explicit weathering scheme developed for use within the UVic ESCM. Steady-state carbonate and silicate weathering rates are calculated for each land grid cell based on the local rock type (Sect. 2.2.1) and runoff (Sect. 2.2.2). In transient model runs, these values are modulated by changes in temperature, atmospheric $\mathrm{CO}_{2}$ concentrations or vegetation productivity, and runoff (Sect. 2.2.3), which are updated on each time step based on model output. Changes in carbonate and silicate weathering rates are returned to the model in the form of a riverine flux of carbon and alkalinity (Sect. 2.2.4), which is routed to the ocean.

\subsubsection{Worldwide distribution of rock types}

The two-dimensionality of the weathering model is rooted in the uneven distribution of rock types across the world. Thus, regions with more active lithologies yield higher weathering rates under similar climate conditions, and these are more sensitive to changes in climate controls than regions predominantly covered by weathering-resistant lithologies (igneous and metamorphic rocks, basalts and granites). Whereas the worldwide distribution of continental rock lithology is well known, there is only limited knowledge of the impact of different rock types on the amounts of riverine exports, therefore any estimation of weathering rates based on local lithological composition is subject to some discrepancy.

In this study we used the lithological distribution paradigm first introduced in GEM-CO $\mathrm{CO}_{2}$, and later published by Amiotte Suchet et al. (2003). The flux of atmospheric/soil $\mathrm{CO}_{2}$ from chemical weathering on each continental grid cell was given an empirical linear relationship to runoff (see Sect. 2.2.2) depending on its assigned predominant lithological category. Rock types, from having the smallest to largest impact on weathering, are classified as follows: plutonic and metamorphic (shield) rocks, sands and sandstones, extrusive igneous (acid volcanic) rocks, basalts, shales and evaporites, and carbonate rocks, the latter of which designs a loose group of predominantly carbonate-based rocks (for example, limestones). Sedimentary rocks (carbonates, shales, sandstones) contain significant amounts of carbonate rocks and thus do not consume atmospheric $\mathrm{CO}_{2}$ as efficiently as other rock types, despite sending a higher riverine flux of weathering products. In the other rock types, the prevalence of carbonate minerals is too variable and difficult to estimate; hence, they are assumed to contain only silicate-weathered minerals.

The adaptation of the rock type distribution map to the UVic model is shown in Fig. 1. The spatial resolution of the UVic model $\left(3.6^{\circ} \times 1.8^{\circ}\right)$ is about 6.5 times coarser than that of the original database $\left(1^{\circ} \times 1^{\circ}\right)$; hence, the adapted rock distribution paradigm was defined according to the partitioning of rock types within the area contained by each UVic model grid cell. The resulting runoff multiplier and carbonate to silicate fractionation therefore becomes a weighted spatial average of all of rock type multipliers in Table 1. 


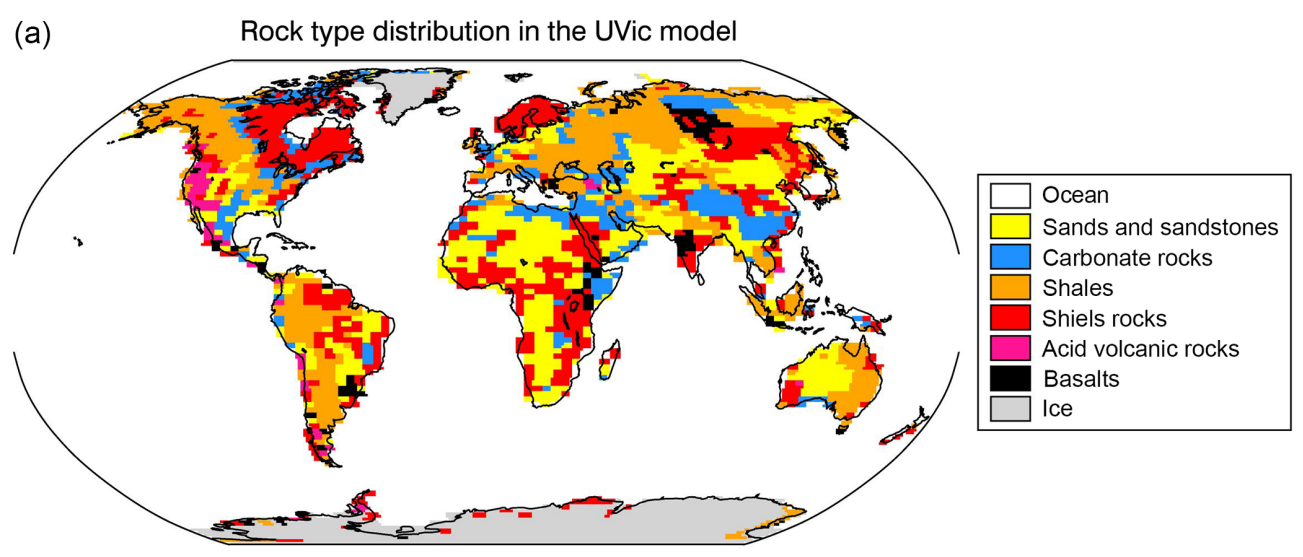

(b)
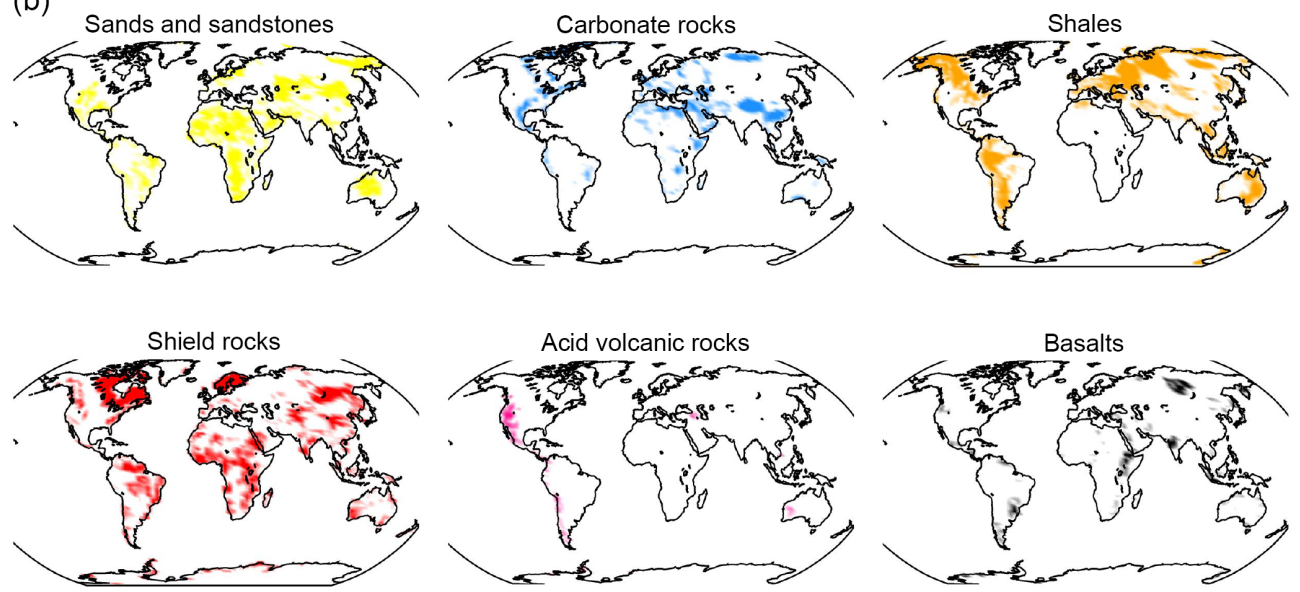

Figure 1. Distribution of the six major rock types for the present day. Presented here are (a) the source data from $\mathrm{GEM}-\mathrm{CO}_{2}(\mathrm{Amiotte}$ Suchet et al., 2003), adapted to the resolution of UVic model, displaying only the dominant lithology in each grid cell, and (b) the interpolated rock type fraction in each grid cell. For the latter, the data are shown ranging from 0 (white) to 1 (full color).

Table 1. Rock type constants used in Eqs. (4) and (5). Here, $k$ represents the weathering rate multiplier, with a higher multiplier signifying a higher concentration of weathering products per unit of runoff (or alternatively, a lower resistance to weathering agents); $\alpha$ denotes the fraction of the given rock type to weather as carbonate rocks. A value of zero means that the rock type consists of silicate minerals only.

\begin{tabular}{lrr}
\hline Lithology & $k$ & $\alpha$ \\
\hline Carbonate rocks & 1.586 & 0.93 \\
Shales & 0.627 & 0.39 \\
Sands and sandstones & 0.152 & 0.48 \\
Basalts & 0.479 & 0 \\
Shield rocks & 0.095 & 0 \\
Acid volcanic rocks & 0.222 & 0 \\
\hline
\end{tabular}

www.earth-syst-dynam.net/8/455/2017/

\subsubsection{Calculating the steady-state weathering rate}

The reference weathering rate is calculated for each individual grid cell based on local steady-state runoff $R_{0}$ (Fig. 2a) and rock type composition. Following Amiotte Suchet and Probst (1995), the local riverine fluxes of bicarbonate ions from carbonate $\left(f_{\mathrm{Ca}}\right)$ and silicate $\left(f_{\mathrm{Si}}\right)$ weathering are computed as

$f_{\mathrm{Ca}}=R_{0} \sum_{i} \operatorname{frac}_{i} k_{i} \alpha_{i}$,
$f_{\mathrm{Si}}=R_{0} \sum_{i} \operatorname{frac}_{i} k_{i}\left(1-\alpha_{i}\right)$,

where $\operatorname{frac}_{i}$ is the fraction of rock type $i$ present in the grid cell, $k_{i}$ is the rock type specific weathering rate multiplier, and $\alpha_{i}$ is the fraction of rock type given to weather as carbonate rocks. The different rock types and their weathering parameters are shown in Table 1. The weathering rate multipliers $\left(k_{i}\right)$ were derived from the data by Amiotte Suchet et al. (2003) and the fractionation of rock types between carbonate and silicate rocks is adapted from the work of Gibbs 
et al. (1999), following the interpretation of Colbourn et al. (2013). The reasoning behind our not including temperature or NPP in the spinup is that the steady-state weathering rates, which depend on the boundary conditions relevant to pre-industrial conditions (including atmospheric $\mathrm{CO}_{2}$ concentrations), must necessarily reflect the steady-state climate and environment.

The resulting steady-state carbonate and silicate weathering rates at pre-industrial $(1800 \mathrm{CE})$ conditions are shown in Fig. 2b. There is a noticeable concentration of $\mathrm{CaCO}_{3}$ weathering in areas of high runoff with bedrock composed predominantly of carbonate rocks (for example, southeastern Asia), whereas $\mathrm{CaSiO}_{3}$ weathering is spread more evenly across the world. It is noteworthy that the Amazon Basin features by far the highest runoff yet produces unremarkable weathering rates (compared to other tropical areas) due to the prevalence of the weathering-resistant shield rocks. The same observation can be used to explain the low weathering rates in central Africa. This weathering distribution compares reasonably well with the $\mathrm{CO}_{2}$ consumption distribution found by Amiotte Suchet and Probst (1995), but it does not reproduce the large values at northern high latitudes (especially in northern Asia) that can be found using the GEM$\mathrm{CO}_{2}$ model. The distribution of bicarbonate fluxes of Gibbs and Kump (1994) displays a somewhat lower equator-topole gradient in weathering rates, and suggests an area of high weathering in the southeast USA which is not reproduced with our model, mainly on account of low runoff in the region. These discrepancies are likely due to precipitation bias in the UVic ESCM. However, both models appear to agree with our finding that southeastern Asia is the region with the highest regional weathering intensity. Globally, the 2-D weathering scheme sends a DIC flux of $0.166 \mathrm{Pg} \mathrm{C} \mathrm{yr}^{-1}$ into the ocean, which is approximately $15 \%$ more than the 0-D model output (0.145 $\mathrm{Pg} \mathrm{C} \mathrm{yr}^{-1}$ ) (Meissner et al., 2012), and on par with previous estimations of pre-industrial global weathering intensity (see, for example, Moon et al., 2014).

\subsubsection{Modulation of weathering rate}

In transient model simulations, the carbonate and silicate weathering rate for each grid cell is modulated by changes in local environmental conditions. They were made dependent on surface air temperature, atmospheric carbon dioxide content, and runoff in a similar manner to previous carbon cycling models. Following Lenton and Britton (2006), we have included the option of replacing the dependency on $\mathrm{CO}_{2}$ concentration by vegetation productivity, which more directly accounts for the impact of biological factors on weathering intensity.

Temperature is a known controller of weathering intensity as higher temperatures increase the kinetic energy of molecules, facilitating the atomic encounters which lead to the chemical dissociation of minerals. Although it is impossible to derive a relationship between temperature and weath- ering rates from first principles, laboratory and field studies have correlated the concentration of bicarbonate ions in a solution to water temperature in order to develop an empirical formulation. For carbonate weathering, we used the results of Harmon et al. (1975), who compared the groundwater temperature and bicarbonate ion concentration of several North American watershed to come up with the following empirical relationship:

$g_{\mathrm{Ca}}(\mathrm{SAT})=1+0.049\left(\mathrm{SAT}-\mathrm{SAT}_{0}\right)$,

where SAT and $\mathrm{SAT}_{0}$ are the transient and steady-state surface air temperature, respectively. For silicate weathering, we used a version of the Arrhenius rate law of Brady (1991) which was adapted into the RokGeM by Colbourn et al. (2013):

$g_{\mathrm{Si}}(\mathrm{SAT})=e^{0.09\left(\mathrm{SAT}-\mathrm{SAT}_{0}\right)}$.

Here, the constant of 0.09 inside the exponential expression was obtained using an activation energy of $63 \mathrm{~kJ} \mathrm{~mol}^{-1}$ for silicate weathering and a global initial temperature of $288 \mathrm{~K}$ (global average pre-industrial temperature). The activation energy is poorly constrained, but has been shown to have little effect on the long-term consumption of atmospheric $\mathrm{CO}_{2}$.

The productivity dependence of weathering serves to illustrate the biological and soil-enhancement factors which control weathering intensity, with vegetation net primary productivity a suitable proxy for biological activity in an area. Lenton and Britton (2006) introduced a simple linear dependence of weathering on productivity based on the steadystate proportion of global productivity to global weathering flux:

$g(\mathrm{NPP})=\frac{\mathrm{NPP}}{\mathrm{NPP}_{0}}$,

where NPP and $\mathrm{NPP}_{0}$ are the transient and steady-state net primary production, respectively, taken explicitly from the output of the coupled land surface scheme MOSES-2 and vegetation module TRIFFID. This formulation works reasonably well in 0-D models with globally summed values of productivity and weathering rate; however, some problems arise when trying to use it in a spatially explicit model due to its inherent assumption that productivity and weathering intensity are directly related at steady state. A good example of this would be at the continental margins of predominantly ice-covered continental landmasses (Greenland, Antarctica) where some of the land may be ice-free but too cold to support any vegetation. However, the presence of nearby ice sheets generates a meltwater runoff flux which greatly enhances weathering, in spite of the lack of vegetation. Therefore, any expansion of vegetation in this area, however small (which is not unrealistic given the extreme warming scenarios examined here), would result in an unreasonable increase in weathering. In order to rectify this situation, we have introduced a modified version of Eq. (8) which calculates the 

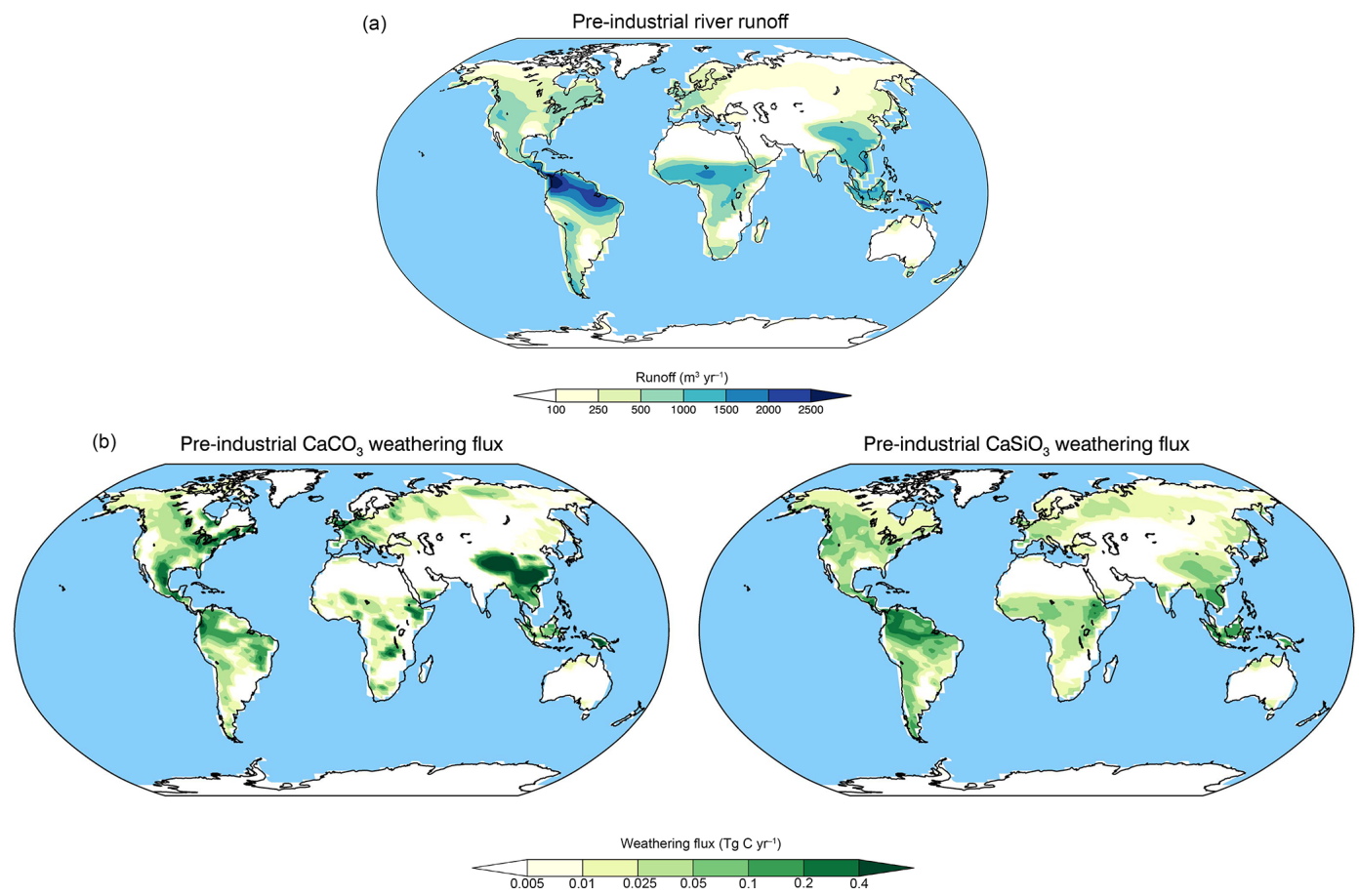

Figure 2. Pre-industrial (year $1800 \mathrm{CE}$ ) setup for our weathering scheme. (a) Model-simulated annual mean river runoff, which is combined with rock type fractions (see Fig. 1) using Eqs. (4) and (5) to produce (b) the carbonate and silicate weathering fluxes at pre-industrial steady state. Note the nonlinear color scales, used here to better display values outside of tropical regions.

increase in local weathering rate when NPP is greater than its steady-state value:

$g(\mathrm{NPP})= \begin{cases}\mathrm{NPP} / \mathrm{NPP}_{0}, & \mathrm{NPP}<\mathrm{NPP}_{0} \\ \left(1+\frac{\left(\mathrm{NPP}-\mathrm{NPP}_{0}\right) / \mathrm{NPP}_{0, \text { global }}}{f_{0} / f_{0, \text { global }}}\right), & \mathrm{NPP} \geq \mathrm{NPP}_{0},\end{cases}$

where $f_{0}=f_{\mathrm{Ca}}+f_{\mathrm{Si}}$ and the "global" indices indicate the globally summed value of that variable. The right-hand term in the brackets is a compensation term, which modifies the increase in weathering based on the relative contribution of the grid cell to the global productivity compared with its contribution to the global weathering flux. This results in a redistribution of NPP-induced changes in weathering without changing the globally summed increase in weathering intensity (this is true only in the absence of other controlling factors, such as temperature). Note that the parameterization is unchanged from Eq. (8) whenever NPP is lower than its initial value, mostly to avoid computing negative values of $g(\mathrm{NPP})$. This has a relatively benign impact on the global result, as the values calculated from Eq. (9) only differ significantly from those of Eq. (8) when NPP is much greater than $\mathrm{NPP}_{0}$.

As an alternative to productivity dependence, we also included the option to parameterize weathering as a function of atmospheric $\mathrm{CO}_{2}$ content, following the approach used in the GEOCARB II model of Berner (1994):

$g\left(\mathrm{CO}_{2}\right)=\left(\frac{2 \frac{p \mathrm{CO}_{2}}{p \mathrm{CO}_{2,0}}}{1+\frac{p \mathrm{CO}_{2}}{p \mathrm{CO}_{2,0}}}\right)^{0.4}$,

where $p \mathrm{CO}_{2}$ and $p \mathrm{CO}_{2,0}$ are the transient and steady-state atmospheric concentration of $\mathrm{CO}_{2}$, respectively. This relationship has long been used to estimate the fertilizing effect of $\mathrm{CO}_{2}$ on land plants, and thus becomes here an indirect parameterization of the biological enhancement of weathering. It can be used in lieu of Eqs. (8) and (9) as a model option.

Runoff is the most widely used factor of weathering intensity as it constitutes a good proxy for the strength of the water cycle in an area. One may consider the fact that high-runoff environments tend to be associated with intense weather activity (the rainforests, for example), and also that stagnant waters quickly become saturated, thus limiting the efficiency of weathering. Given that we already include runoff in the calculation of steady-state weathering, the transient runoff dependency is a simple adjustment following Berner (1994):

$g_{\mathrm{Ca}}(R)=\frac{R}{R_{0}}$,
$g_{\mathrm{Si}}(R)=\left(\frac{R}{R_{0}}\right)^{0.65}$,

where $R$ and $R_{0}$ are the transient and steady-state river runoff, respectively, which are also taken explicitly from the 
output of the land surface scheme MOSES-2. The difference between the formulations for carbonate and silicate weathering is an empirical correction based on the assumption that bicarbonates from the weathering of silicate rocks are more diluted in rivers than for carbonate weathering. The value of 0.65 in Eq. (12) was taken from Berner (1994); although the value itself has a large margin of error, it has been shown to have only a modest effect on the overall efficiency of the weathering feedback mechanism.

To summarize, we have developed a two-dimensional weathering scheme whereby the steady-state values of carbonate and silicate weathering fluxes (see Sect. 2.2.2) are modulated by changes in temperature, vegetation productivity (alternatively: atmospheric $\mathrm{CO}_{2}$ concentration), and runoff. Thus the complete weathering parameterizations take the form

$$
\begin{aligned}
& F_{\mathrm{Ca}}=f_{\mathrm{Ca}} \cdot g_{\mathrm{Ca}}(\mathrm{SAT}) \cdot g(\mathrm{NPP}) \cdot g_{\mathrm{Ca}}(R), \\
& F_{\mathrm{Si}}=f_{\mathrm{Si}} \cdot g_{\mathrm{Si}}(\mathrm{SAT}) \cdot g(\mathrm{NPP}) \cdot g_{\mathrm{Si}}(R) .
\end{aligned}
$$

Weathering is calculated in each individual land grid cell, and routed to the coastal ocean as fluxes of alkalinity and dissolved inorganic carbon. The UVic model divides the continental land area into a set of pre-determined drainage basins, and the riverine fluxes into the oceans are spread evenly across the continental margins (land grid cells adjacent to ocean) for each drainage basin (see Weaver et al., 2001). The input of weathering products is implemented into the model as riverine fluxes; however, they are immediately redistributed evenly across the ocean surface layer.

\subsubsection{Effects of weathering on ocean biogeochemistry}

In the UVic ESCM, weathering does not have a direct impact on atmospheric or land surface carbon; its effects are prescribed through the riverine exports of weathering products which are sent to the ocean and modify its chemical composition. The chemical weathering processes are described by Eq. (1) (carbonate) and Eq. (2) (silicate), both resulting in a flux of two moles of bicarbonate ions $\left(\mathrm{HCO}_{3}^{-}\right)$. The flux of dissolved inorganic carbon $\left(F_{\mathrm{DIC}}\right)$ is counterbalanced by the consumption of atmospheric carbon dioxide during the weathering reactions, leaving a net DIC flux of $1 \mathrm{~mol}$ for carbonate weathering, and none for silicate weathering; a constant term was also added to represent the contribution of volcanic outgassing to global carbon emissions (which is not included in the UVic model):

$$
F_{\text {DIC }}=F_{\mathrm{Ca}}+F_{\text {volc }} .
$$

Given that, in the absence of external forcings, the $\mathrm{CO}_{2}$ consumption by silicate weathering is meant to counter the intake of carbon from the geologic reservoir from volcanic eruptions, we set the constant term $F_{\text {volc }}$ to equal the steadystate flux of silicate weathering $\left(F_{\mathrm{volc}}=F_{\mathrm{Si}, 0}\right)$. Meanwhile, the net flux of alkalinity $\left(F_{\mathrm{ALK}}\right)$ remains equal to the flux of bicarbonate ions. The above discussion is summarized in the following set of equations, which describes the partitioning of carbonate weathering and silicate weathering fluxes into dissolved inorganic carbon and alkalinity fluxes, which are then globally summed and fed to the ocean biogeochemistry module:

$F_{\mathrm{DIC}}=F_{\mathrm{Ca}}+F_{\mathrm{Si}, 0}$,

$F_{\mathrm{ALK}}=2 F_{\mathrm{Ca}}+2 F_{\mathrm{Si}}$.

Note that our choice of $F_{\text {volc }}$ effectively equilibrates ocean biogeochemistry during equilibrium runs $\left(F_{\mathrm{ALK}, 0}=\right.$ $\left.2 F_{\text {DIC,0 }}\right)$. The values calculated here represent net fluxes over the entire surficial (atmosphere-land-ocean) reservoir, and in particular the simplification for the net flux of DIC is based on the assumption that the consumption of $\mathrm{CO}_{2}$ from the atmosphere is immediately balanced by an equivalent outgassing of carbon from the ocean. This would be true in general, given that the timescale of the weathering negative feedback mechanism far exceeds that of atmosphere-ocean mixing; however, in the timescales considered here $\left(10^{3}-\right.$ $10^{4}$ years) there would be some delay between the consumption of $\mathrm{CO}_{2}$ from the atmosphere and the release of $\mathrm{CO}_{2}$ in the ocean following $\mathrm{CaCO}_{3}$ burial - this delay comes from the average time it takes for the calcium and carbonate ions on the seawater to precipitate again as calcium carbonate, which releases a molecule of carbon dioxide. This delay would not significantly alter the impact of weathering on atmospheric geochemistry, but could reduce by as much as $10 \%$ the rate at which alkalinity increases in the ocean (Colbourn et al., 2013).

\subsection{Steady-state weathering and description of transient model simulations}

Pre-industrial steady-state weathering was obtained by integrating the model for over 20000 years under year 1800 boundary conditions, using rock type dependency and distribution as detailed in Sects. 3.1.1 and 3.1.2. Land-to-ocean weathering fluxes stabilized in less than $10^{3}$ years, on account of runoff being mostly computed from atmospheric output. However, the fixing of deep ocean alkalinity and dissolved inorganic carbon (DIC) content from transient to steady-state values (along with the non-constant weathering scheme) would have required as many as $10^{5}$ model years an impossibly long simulation time given the level of complexity of the UVic model. Hence, we extracted the model steady state after $10^{4}$ years, but kept the background steadystate run ongoing concomitantly with the transient model simulations in order to correct the output of the latter based on changes in the former; at the time of extraction, the ocean DIC and alkalinity content were about $7-8 \%$ away from their equilibrium value. Each transient simulation was forced with the historical natural and anthropogenic carbon emission for 200 years; at year 2000 an additional $5000 \mathrm{Pg} \mathrm{C}$ was emitted 
over 1 year (unless otherwise indicated), and carbon emissions were set to zero thereafter. All simulations were carried out for a period of 10 millennia, ending at year 12000 .

A total of eight model versions were integrated to year 12000 , which we classified into three groups of experiments (see Table 2 for a description of all experiments). Group A (Sect. 3.1) experiments investigate the impact of the intensity and span of the prescribed carbon emissions. Simulation $\mathrm{A} 0$ is the basic emission scenario outlined in the above paragraph, and thus served as the main control run for this paper. Simulation A1 is similar but used a more conservative estimate of $1000 \mathrm{PgC}$ for future anthropogenic emissions. Finally, simulation A2 extended the carbon emission total of $5000 \mathrm{Pg}$ over a much longer period: emissions were increased linearly until reaching double the current (year 2000) carbon emissions; the remaining carbon emissions were then distributed evenly during the period from 2050 to 3000 , then set to zero thereafter. Although distributed over a longer period, the total carbon emissions remained unchanged from our control run A0.

Group B experiments (Sect. 3.2) compare the various model representations of the biological enhancement factor. In simulation B1, we replaced the NPP dependence term $g$ (NPP) in Eqs. (13) and (14) with $g\left(\mathrm{CO}_{2}\right)$ from Eq. (10) on all grid cells. Although carbon dioxide concentrations in the atmosphere are known to vary slightly across the surface of the Earth, in the UVic model $p \mathrm{CO}_{2}$ is a global term with no defined spatial variability. This effectively removes the twodimensionality of the biological feedback term, leaving temperature as the sole spatially explicit variable. Runoff does not vary much unless there are major changes in hydrology or ice sheet distribution, neither of which were considered in our simulations. A further simplification was made in simulation B2 by removing the biological enhancement factor altogether and incorporating a parameterization that is only based on the temperature-dependent part of our spatially explicit scheme.

Group C experiments (Sect. 4.3) compare the relative importance of carbonate and silicate weathering through their impacts on riverine fluxes of alkalinity and DIC. In simulation $\mathrm{C} 1$, we eliminated the silicate weathering feedback $\left(F_{\mathrm{Si}}=f_{\mathrm{Si}}\right)$, leaving only the carbonate weathering part of the parameterization. Likewise, in simulation $\mathrm{C} 2$, the carbonate weathering feedback was negated $\left(F_{\mathrm{Ca}}=f_{\mathrm{Ca}}\right)$, isolating the impact of the silicate weathering feedback. Finally, in model version $\mathrm{C} 3$ we eliminated both carbonate and silicate weathering feedbacks to maintain constant weathering fluxes (at steady-state values) throughout the simulation. This last model version effectively simulates the carbon sequestration potential of the oceans in the absence of the weathering feedback mechanism.

For each of the model versions outlined above (with the exception of $\mathrm{C} 1$ and $\mathrm{C} 2$ ), an identical setup was used with a zero-dimensional version of the weathering model whereby weathering rates were calculated based on global, rather than local changes in the control parameters (temperature, NPP, runoff); these 0-D model versions are identified in the figures using the "**" notation (for example, "A0*" refers to the zerodimensional version of simulation A0). The code for these 0 -D model versions was developed in an earlier study of terrestrial weathering changes with the UVic model (Meissner et al., 2012).

\section{Results}

\subsection{Group A results}

The time series of $\mathrm{CO}_{2}$ concentration in the atmosphere as well as weathering fluxes of carbon and alkalinity are shown in Fig. 3a for each of the pulse (Group A) scenarios (solid lines), and compared with results from similar scenarios using the $0-\mathrm{D}$ version of the model (dotted lines). For all simulations, the 2-D model was always more efficient in removing $\mathrm{CO}_{2}$ from the atmosphere than its 0-D counterpart. This can be partially explained by the initial global total weathering being slightly higher in the 2-D model (see Sect. 2.2.2); however, this cannot account for alkalinity weathering increasing nearly 3 times as much in the 2-D model as it does in the 0 -D version (interestingly, 0 -D weathering rates seem to be slightly higher than 2-D values for scenario A1). Instead, we propose that this is a natural consequence of using a twodimensional approach. Temperature, productivity, and runoff are closely related, as all three are positively affected by the increase in atmospheric $\mathrm{CO}_{2}$ : temperature from the greenhouse effect, NPP through the $\mathrm{CO}_{2}$ fertilization of plants, and runoff as a result of both a temperature (hence precipitation) increase and the $\mathrm{CO}_{2}$-induced increase in plant water-use efficiency. Vegetation productivity also reacts positively to increases in temperature in extratropical regions, although this effect could be overcompensated for by an opposite reaction in tropical regions, where temperatures exceed the threshold for optimized plant growth (Matthews et al., 2005; Matthews et al., 2007). This means that areas which see a large increase in one variable will more often than not see equally large increases in one or both of the other variables, further enhancing the local increase in weathering rates. A zerodimensional model would not be able to create this effect because it uses globally summed or averaged variables. This is especially important with regard to temperature, as the global average would be dominated by oceanic SAT changes, which tend to be smaller than continental SAT changes.

Scenario A2, when compared to A0, suggests that the ability of the Earth system to recover from anthropogenic emissions is essentially independent of the rate at which the emissions occur. Atmospheric $\mathrm{CO}_{2}$ concentrations recovered more slowly in the gradual emissions scenario at first since weathering fluxes were not increased as much, but the gap between the two curves gradually narrowed after A2 emissions ended at year 3000 . We found a modest difference of $13 \mathrm{ppm}$ in atmospheric $\mathrm{CO}_{2}$ concentration between $\mathrm{A} 0$ and 

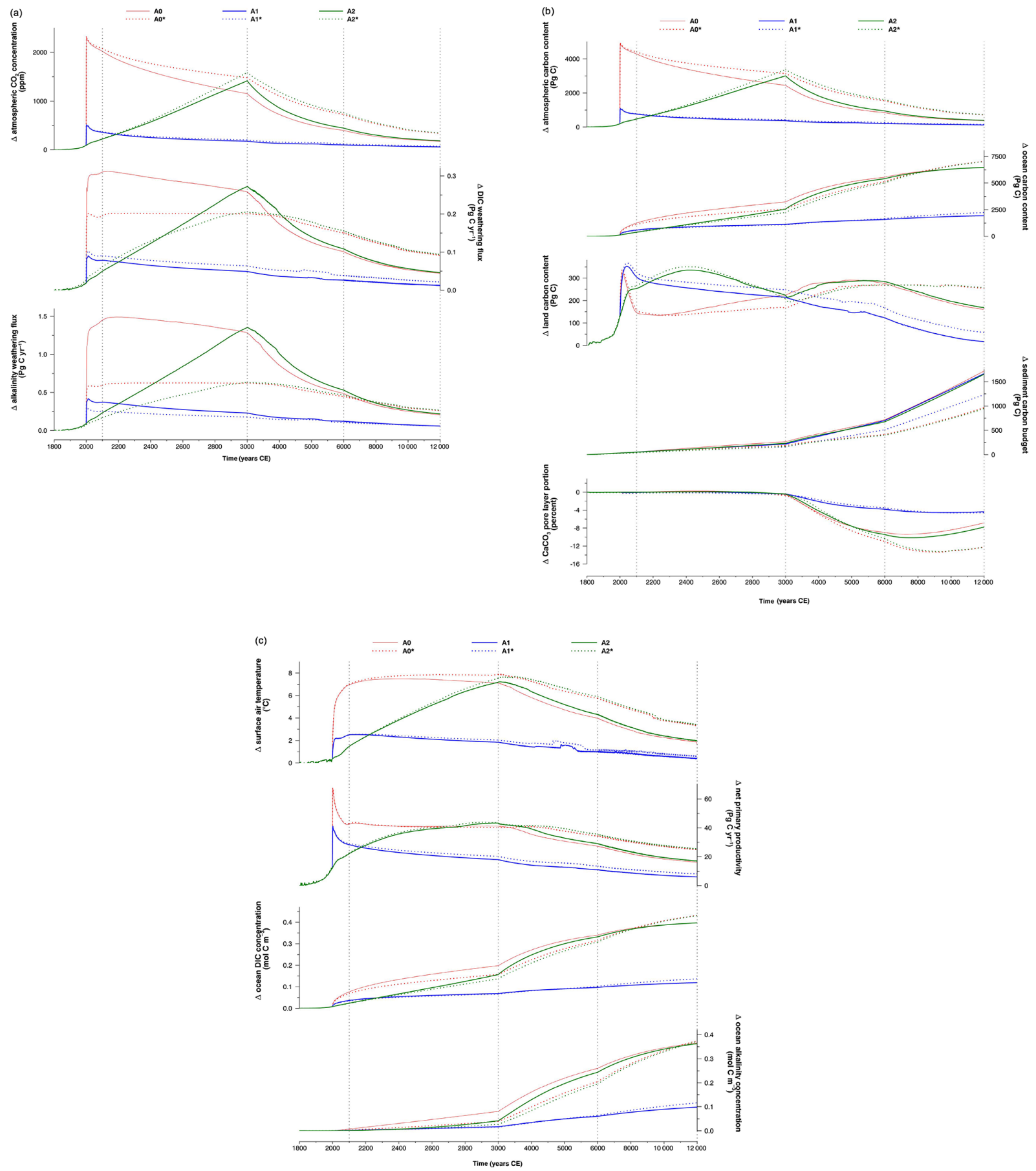

Figure 3. Time series of simulated changes in various globally averaged or summed model outputs for Group A scenarios, compared with pre-industrial steady-state values. These scenarios include A0 (high-amplitude pulse), A1 (low-amplitude pulse), A2 (gradual emissions), and their zero-dimensional counterparts (indicated by the "**" symbol). Shown here are (from top to bottom): (a) atmospheric $\mathrm{CO}_{2}$ concentrations, and weathering fluxes of DIC and alkalinity; (b) global carbon differences for atmospheric, ocean, land, and sediment reservoirs; and (c) surface air temperature, net primary productivity, and oceanic concentrations of DIC and alkalinity. Note the different scales along the time axis, which change at years 3000 and 6000. Vertical dashed lines are used to indicate times for which results are shown in Figs. 4 , 5, and 7. The curves shown here represent experiments A0 (red), A1 (blue), and A2 (green), with dashed colored lines representing the zero-dimensional equivalent model version. 
Table 2. Description of each experiment carried out in this study. The emission total is the total amount of carbon emissions; the emission total is divided equally among the number of time steps during the emission period. For the biological factor, "NPP" refers to Eq. (9), "Atm. $\mathrm{CO}_{2}$ " to Eq. (10), and "None" signifies that this part of the weathering scheme is ignored. Finally, when the $\mathrm{CaCO}_{3}$ switch is $\mathrm{OFF}$, the amount of carbonate weathering produced by the model is set to its pre-industrial value for the duration of the simulation, similarly for when the $\mathrm{CaSiO}_{3}$ switch is OFF.

\begin{tabular}{llcllll}
\hline Group & $\begin{array}{l}\text { Experiment } \\
\text { name }\end{array}$ & $\begin{array}{c}\text { Emission total } \\
(\mathrm{Pg} \mathrm{C})\end{array}$ & $\begin{array}{l}\text { Emission period } \\
\text { (years CE) }\end{array}$ & $\begin{array}{l}\text { Biological } \\
\text { parameter }\end{array}$ & $\begin{array}{l}\mathrm{CaCO}_{3} \\
\text { weathering } \\
\text { switch }\end{array}$ & $\begin{array}{l}\mathrm{CaSiO}_{3} \\
\text { weathering } \\
\text { switch }\end{array}$ \\
\hline $\mathrm{A}$ & $\mathrm{A} 0$ & 5000 & $2000-2001$ & NPP & ON & ON \\
& A1 & 1000 & $2000-2001$ & NPP & ON & ON \\
& A2 & 5000 & $2000-3000$ & NPP & ON & ON \\
\hline B & B1 & 5000 & $2000-2001$ & Atm. $\mathrm{CO}_{2}$ & ON & ON \\
& B2 & 5000 & $2000-2001$ & None & ON & ON \\
\hline C & C1 & 5000 & $2000-2001$ & NPP & ON & OFF \\
& C2 & 5000 & $2000-2001$ & NPP & OFF & ON \\
& C3 & 5000 & $2000-2001$ & NPP & OFF & OFF \\
\hline
\end{tabular}

A2 at year 12000 (8 ppm when comparing both 0-D runs), which is comparable to, if not a little larger than, the difference between the pulse and IPCC A2 simulations in Meissner et al. (2012), in which a $5000 \mathrm{Pg} C$ pulse was spread over 300 years. Given that the longer the carbon emissions are spread out over time, the longer it takes for atmospheric $\mathrm{CO}_{2}$ levels to catch up to a pulse scenario, we can surmise that pulse scenarios would overestimate the ability of the weathering feedback mechanism to remove carbon from the atmosphere in the next several millennia, unless a way is found to mitigate anthropogenic emissions within the next century.

Time series of various carbon reservoirs for Group A scenarios are shown in Fig. 3b. The ocean reservoir content at year 12000 was nearly identical for scenarios A0 and A2, indicating that the ocean was even more indifferent to the rate of carbon emissions than the atmosphere. Zero-dimensional model ocean carbon exceeded the 2-D output at around year 8500 for scenarios A0 and A2, due to the fact that there was more carbon remaining in the atmosphere-ocean system. It is interesting that the land and sediment carbon reservoirs behaved differently from other reservoirs in cases of large or extended carbon emissions. The latter (and associated temperature anomalies) in A0 and A2 appeared to have a counterproductive effect on land carbon content, which was not seen under the more modest temperature increase in simulation A1. If anything, this results points out the inability of the land reservoir to store any significant amount of excess carbon from the atmosphere on millennial timescales. Finally, the sediment carbon curve also behaved somewhat counterintuitively, as all three 2-D pulse scenarios produced a comparable increase in sediment carbon content, regardless of emission rate or amount of carbon released. For the 0-D model versions, total $\mathrm{CaCO}_{3}$ sediment budget increased more rapidly for scenario A1 despite lower amounts of carbon emitted. These results arise because the solubility of cal- cium carbonate in seawater, which determines its precipitation rate, depends on a delicate balance which involves ocean temperature (increasing solubility at higher solvent temperatures), alkalinity, and calcite concentration. Oceans in scenario $\mathrm{A} 1$ contained less $\mathrm{CO}_{2}$ and $\mathrm{CaCO}_{3}$ but were also cooler than in $\mathrm{A} 0$ and $\mathrm{A} 2$, which may explain why the total accumulation of $\mathrm{CaCO}_{3}$ sediments was comparable between all three scenarios. However, even though the buried mass of $\mathrm{CaCO}_{3}$ was constantly increasing in all scenarios, the pore layer mass depicts a more accurate version of what happens with ocean biogeochemistry during that time. After year 3000, the pore layer mass in all scenarios become negative, indicating that the rate of dissolution of carbonates exceeds the burial rate. This is to be expected and represents a shoaling of the lysocline in response to a sudden increase in oceanic carbon content as ocean $p \mathrm{CO}_{2}$ tries to reach equilibrium with atmospheric $p \mathrm{CO}_{2}$.

Global changes in surface air temperature, vegetation NPP, and surface runoff are shown in Fig. 4 at various times during the 10 000-year simulation. As seen in Fig. 4a, the most significant changes in temperature mostly occurred poleward of $60^{\circ}$ of latitude; however, there were also increases in many tropical regions. These results are to be expected given the static nature of wind fields in the UVic model, which prevent a reorganization of atmospheric circulation and thus trap the warm anomalies in the tropics. Figure $4 \mathrm{a}$ (see also Fig. 3c) also reveals that the cooling effects of carbon sequestration were not felt until well after year 3000, despite atmospheric $\mathrm{CO}_{2}$ concentrations being decreased by nearly $1000 \mathrm{ppm}$ between years 2000 and 3000; this is simply due to the thermal inertia of the ocean (Matthews and Caldeira, 2008). By year 12000 , temperature anomalies across the globe became fairly uniform, with every area averaging $1-$ $2^{\circ} \mathrm{C}$ warmer than pre-industrial state. 

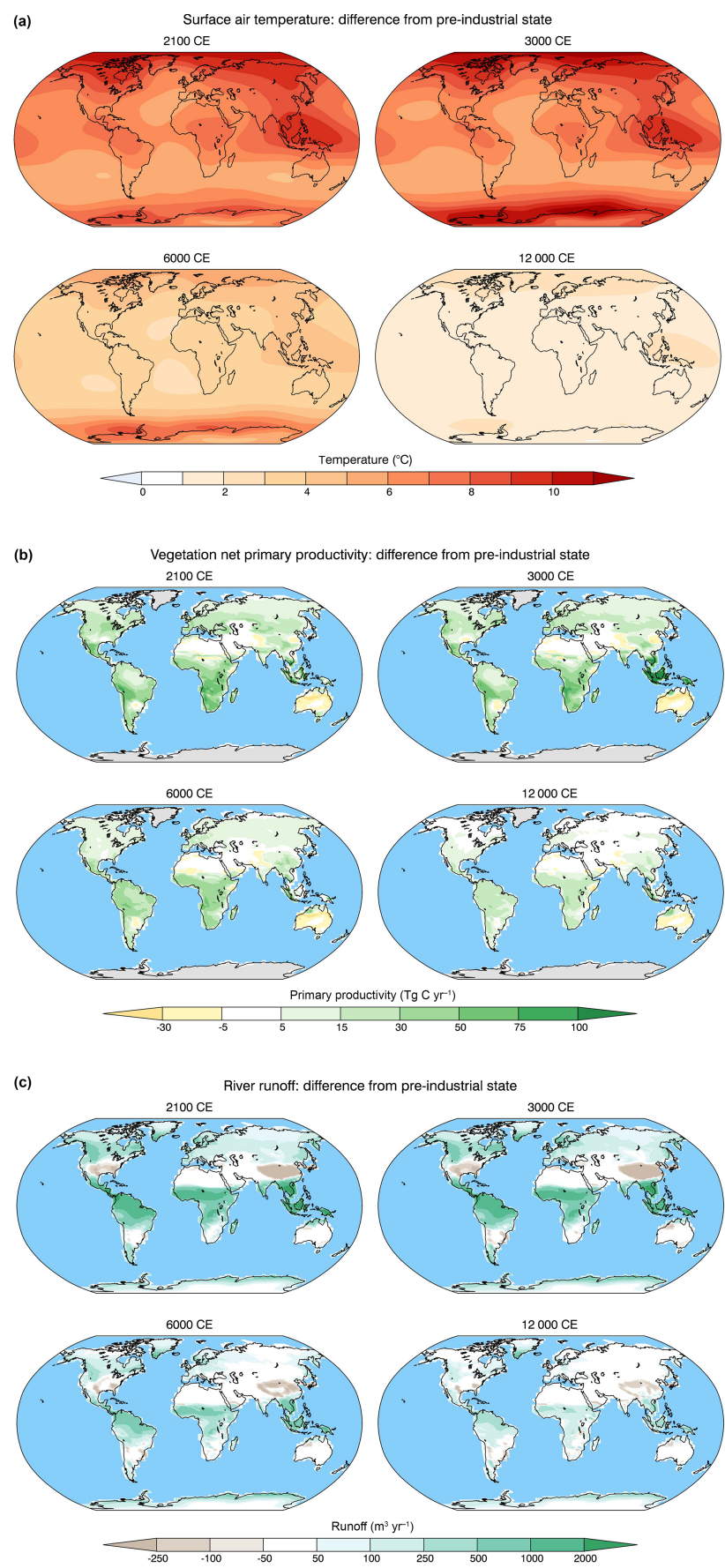

Figure 4. Spatial distribution of changes in (a) surface air temperature; (b) vegetation net primary productivity; and (c) river runoff for experiment A0 from pre-industrial (year $1800 \mathrm{CE}$ ) state to years 2100, 3000, 6000, and $12000 \mathrm{CE}$. Nonlinear color scales are used in (b) and (c) to better display the results for the later stages of the model simulation.

Changes in vegetation net primary productivity are shown in Fig. 4b. Most of the world saw an increase in vegetation activity from the direct effect of $\mathrm{CO}_{2}$ fertilization, with the exception of desert areas which remained the same (Africa,
Asia) or become more arid (Australia). Changes in NPP also correlated well with changes in river runoff (Fig. 4c); this is mainly a consequence of the effect of increased $\mathrm{CO}_{2}$ concentrations on plants, which optimizes vegetation water-use efficiency, leading to an increase in soil moisture and therefore runoff (Nugent and Matthews, 2012; Cao et al., 2010). The very large NPP increase in Indonesia around year 3000 was likely caused by the replacement of rainforest by the much more productive $\mathrm{C}_{4}$ grasses, and further enhanced by a 1000 -year legacy of high- $\mathrm{CO}_{2}$ fertilization. The validity of this outcome, and that of the $9{ }^{\circ} \mathrm{C}$ surface air temperature increase over the region, which is the apparent cause of this shift in vegetation regime, can be put into doubt. It is possible that the tropical forests would attempt to resist the extreme warming through increased evapotranspiration rates, for example, to avoid being exposed to temperatures that would be threatening to their survival. It is also possible that, due to the short timescale of the perturbation (a few thousand years), plant species would not have time to adapt to the rapid warming and would indeed die off and be replaced by a better suited plant functional type - this could help explain the extremely high temperature increase over the region. Other tropical forests do not, in fact, show this behavior. The Amazonian forest, in particular, remains remarkably stable over the same time period, with much smaller changes in NPP and a smaller increase in surface air temperature over the region as well.

The resulting impacts of these changes in temperature, vegetation productivity, and runoff on $\mathrm{CaCO}_{3}$ and $\mathrm{CaSiO}_{3}$ weathering are shown in Fig. 5. A qualitative visual assessment of the results revealed that changes in weathering appeared to be more strongly correlated to changes in NPP and, to a lesser extent, runoff. The influence of rock type distribution was also noticeable, especially on the carbonate/silicate weathering partitioning, while temperature had an overall modest impact. Most areas saw a moderate to high increase in both weathering types, with the exception of arid areas (deserts and ice caps) which experienced a minor decrease in weathering. The most significant change occurred in central western Asia (Kazakhstan), where a favorable combination of low initial NPP and a high enough initial weathering rate made it possible for weathering values to become excessively high when the increase in temperature led to a drastic (and very temporary) increase in vegetation productivity during the third millennium CE. This anomaly all but disappeared in later snapshots of the simulation, once global temperatures were no longer warm enough to sustain such high levels of vegetation productivity. Indonesia also saw a large increase in silicate weathering rates, on account of all three controlling parameters increasing by a large margin in the area, coupled with a predominantly silicate-heavy lithology. In later stages of the model simulation, weathering rate anomalies had mostly retreated to the tropical latitudes, where productivity and runoff anomalies persisted the longest; elsewhere 
Weathering flux difference from pre-industrial state
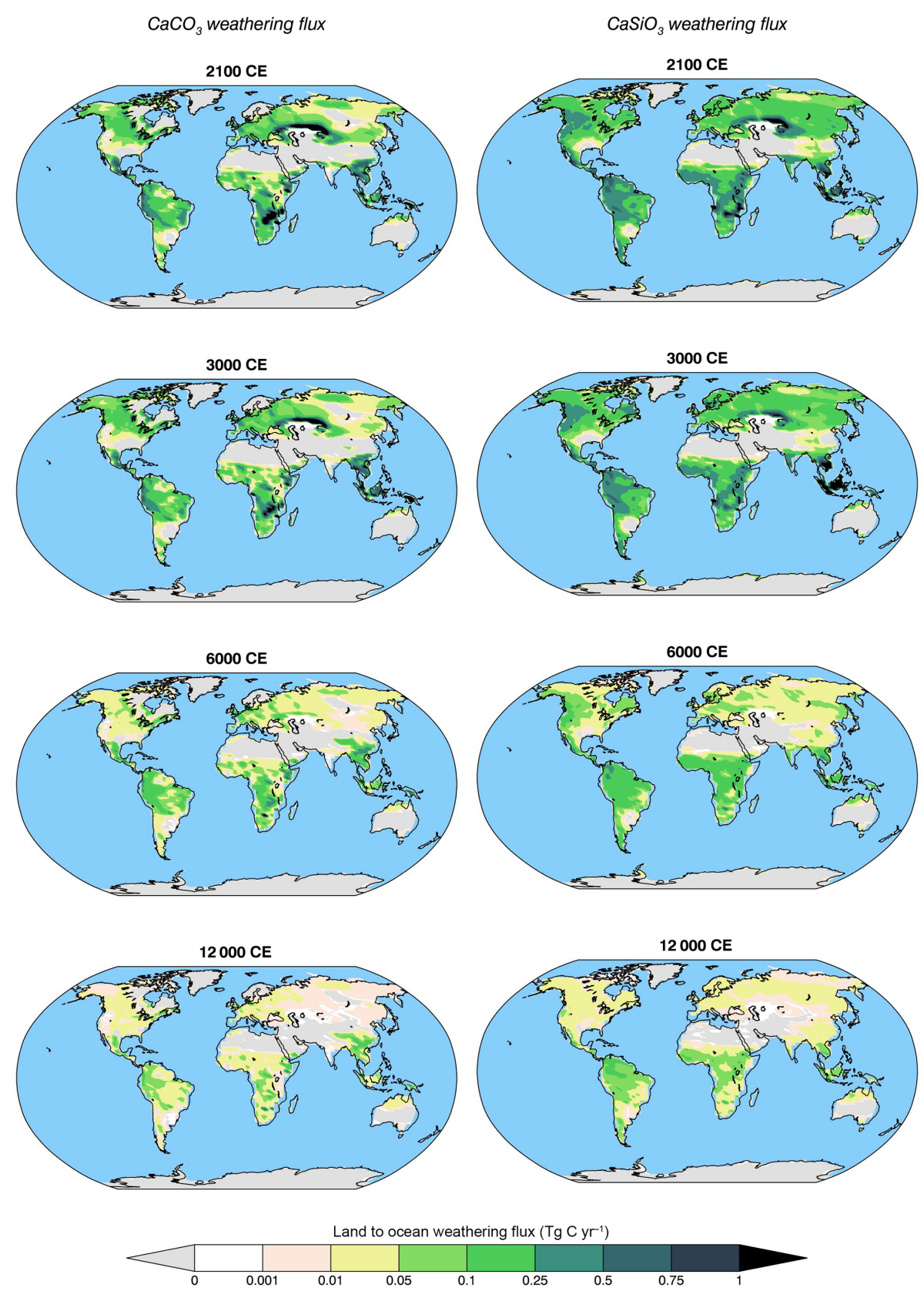

Figure 5. Spatial distribution of changes in carbonate $\left(\mathrm{CaCO}_{3}\right)$ and silicate $\left(\mathrm{CaSiO}_{3}\right)$ weathering for experiment $\mathrm{A} 0$ from pre-industrial (year $1800 \mathrm{CE}$ ) steady state to years $2100,3000,6000$, and $12000 \mathrm{CE}$. Note the nonlinear color scale, used to better display values during the later stages of the model simulation.

the increase in weathering rates was reduced to below $10 \%$ of their value during the third millennium CE.

\subsection{Group B results}

The purpose of this group of experiments was to assess the importance of including a parameterization for NPP (A0) rather than atmospheric $\mathrm{CO}_{2}$ concentration (B1), or a weath- ering scheme based exclusively on temperature and runoff feedbacks (B2). Model output for atmospheric $\mathrm{CO}_{2}$ concentration and weathering fluxes is shown in Fig. 6a. The results strongly suggest that using vegetation productivity rather than $\mathrm{CO}_{2}$ as a proxy for biological activity makes weathering fluxes much more sensitive to overall climate and environmental changes. Weathering fluxes peaked around year 2200, and the increase for simulation A0 (using NPP) was 
twice that for simulation $\mathrm{B} 1$ (using $\mathrm{CO}_{2}$ ), and about three times larger than for simulation B2 (with no biological effect); in other words, adding a deliberate NPP dependence tripled the weathering increase compared to the case using a temperature dependence only. This is likely a result of rapid vegetation expansion in the high latitudes and the appearance of warm-adapted and more productive biomes in the temperate regions, which was taken into account in A0 but not in the Group B model versions. As a result, the recovery time of atmospheric $\mathrm{CO}_{2}$ levels was much faster in $\mathrm{A} 0$, and vegetation productivity rapidly dropped below the levels of B1 and B2 (not shown). Interestingly, after year 7000 the weathering DIC flux in simulation A0 fell below that of B1, indicating that from that point onward the parameterization in $\mathrm{B} 1$ was more effective in removing $\mathrm{CO}_{2}$ from the atmosphere. This feature does not appear in the 0-D model results, where DIC weathering fluxes always remained higher in the productivity-dependent model version. As mentioned in Sect. 3.1, it is possible that the increased effectiveness of the 2-D weathering parameterization (compared to 0-D) is caused by the coincidence of large temperature/runoff increases within areas that also see a large increase in vegetation NPP. This could be diagnosed from model output by isolating all of the factors which affect weathering rates, but such an analysis is beyond the scope of this paper. The most logical answer to why the weathering rates in $\mathrm{A} 0$ drop below those of B1 is that the temperature (and NPP) in A0 have dropped so much below that of $\mathrm{B} 1$ that weathering rates in B1 manage to exceed those in A0 despite using a scheme which does not as efficiently represent the strength of the biological enhancement of weathering.

Figure $6 \mathrm{~b}$ displays the time series of ocean and sediment carbon, as well as three parameters which are used to analyze the evolution of calcite sedimentation in the model: $\mathrm{CaCO}_{3}$ production, pore layer portion, and dissolution. In contrast to 0 -D versions of the model, there was a clear convergence of all three 2-D curves for ocean carbon content resulting from a substantial drop in weathering rates during the latter half of the simulation period. The rate of increase in $\mathrm{CaCO}_{3}$ buried mass was slower in model versions with lower weathering rates; this surprisingly differs from Fig. 3b, where there was not much difference between the three model versions. However, the 0-D curves still displayed a significant lag behind their 2-D counterparts. The pore layer portion remained unchanged during the first thousand model years after the introduction of the $5000 \mathrm{Pg} \mathrm{C}$ pulse, thus mirroring the results of Meissner et al. (2012). Higher biological activity and carbonate concentration in the surface ocean due to warmer temperatures was found to lead to a sharp increase in calcium carbonate formation and precipitation; this was balanced by a rising of the carbon compensation depth (CCD) in the deep ocean fueled by the rising acidity of the ocean, which increased the overall dissolution rate of calcite. As the more immediate effects of the carbon emission pulse receded, oceans became cooler and calcite forma- tion weakened, while dissolution kept increasing for another 1000 years. This created an unbalance in the $\mathrm{CaCO}_{3}$ pore layer fraction which appears from year 4000 onward. Note that even though dissolution rates in the deep ocean exceeded calcite production in the surface layer, there was still an overall increase in $\mathrm{CaCO}_{3}$ buried mass due to the enormous increase in oceanic carbon content.

Figure 7 displays the spatial distribution of $\mathrm{CaCO}_{3}$ and $\mathrm{CaSiO}_{3}$ weathering changes at various points of the simulation timeline for model version B1. Several areas of higher weathering from Fig. 5 are completely absent (central Eurasia), and some others are greatly reduced (tropical Africa). These are the most important examples of how the vegetation productivity parameterization can greatly enhance carbonate weathering locally, and silicate weathering worldwide (see Fig. 4b). Weathering rates are generally higher in A0 throughout the simulation, but it should be noted that in some areas in the final snapshot (year $12000 \mathrm{CE}$ ) weathering in A0 falls below that of B1. Since the only difference between B1 and $\mathrm{B} 2$ is the presence of (globally averaged) atmospheric $\mathrm{CO}_{2}$ concentration as a factor, the equivalent figure for model version B2 (not shown) would have been extremely similar to $\mathrm{B} 1$, with the magnitude of warming being a bit higher in $\mathrm{B} 1$ given that globally increased $\mathrm{CO}_{2}$ would augment weathering rates everywhere.

\subsection{Group C results}

The purpose of this group of experiments was to isolate and compare the individual contributions of carbonate (C1) and silicate $(\mathrm{C} 2)$ weathering to the global feedback mechanism, and to compare them with a scenario where this negative feedback does not exist (C3). The time series of atmospheric $\mathrm{CO}_{2}$ concentrations and DIC/alkalinity weathering are shown in Fig. 8a. After 500 years of roughly similar behavior, the curves diverged into three distinct narratives. By year 12000 , about $33 \%$ of the emitted carbon was still in the atmosphere for model version C3 (constant weathering), whereas about $20 \%$ of the carbon remained for the $\mathrm{C} 1$ (change in carbonate weathering only), and $10 \%$ for $\mathrm{C} 2$ (change in silicate weathering only) and A0 (control run). This is due to the immediate effect of carbonate weathering, which increase alkalinity content in the ocean faster than the rate at which the precipitation of calcium carbonate increases. Over timescales of $10^{5}$ years or more, we would expect the $\mathrm{C} 3$ curve to catch up to $\mathrm{C} 1$ as increased calcite burial releases carbon dioxide back to the ocean, negating the carbon removal at the surface; this outcome is verified in the million-year simulations of Colbourn et al. (2013) but impossible to replicate here due to the timescales involved. The C2 model version yielded very similar results to A0, which included the impacts of both carbonate and silicate weathering. The difference between the two was greater initially, as the additional alkalinity provided by carbonate weathering further enhances the oceanic uptake of $\mathrm{CO}_{2}$ from the at- 

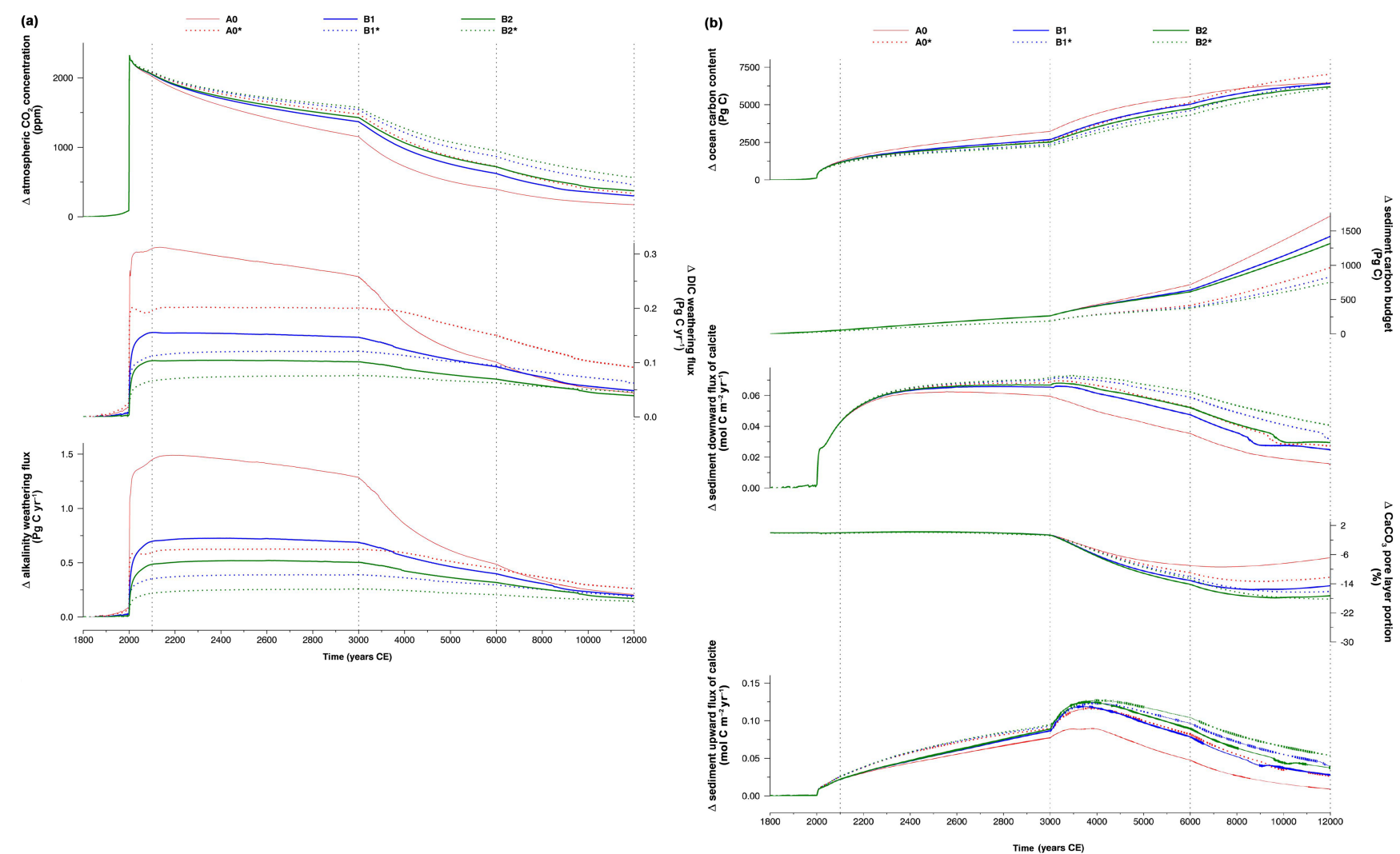

Figure 6. Time series of simulated changes in various model outputs for Group B scenarios, compared with pre-industrial steady-state values. These scenarios include A0 (dependence on temperature, NPP, and runoff), B1 (dependence on temperature, atmospheric $\mathrm{CO}_{2}$, and runoff), and B2 (dependence on temperature and runoff only), as well as their zero-dimensional counterparts (indicated by the "**" symbol). Shown here are (from top to bottom) (a) atmospheric $\mathrm{CO}_{2}$ concentrations and weathering fluxes of DIC and alkalinity, and (b) oceanic carbon difference, sediment carbon difference, downward flux of calcite into sediments, calcite pore layer portion, and dissolution of calcite in sediments. Note the different scales along the time axis, which change at years 3000 and 6000 . Vertical dashed lines are used to indicate times for which results are shown in Figs. 4, 5, and 7. The curves shown here represent experiments A0 (red), B1 (blue), and B2 (green), with dashed colored lines representing the zero-dimensional equivalent model version.

mosphere, but the gap gradually narrowed as the mediumterm impacts of carbonate weathering faded away. Could the model run have been extended to hundreds of thousands of years, we would have seen a return to pre-industrial levels for both the A0 and $\mathrm{C} 2$ model versions. Estimates for the lifetime of anthropogenic $\mathrm{CO}_{2}$ have varied from a few (Sundquist, 1991; Archer et al., 1997) to several (Berner and Kothavala, 2001; Archer, 2005) hundreds of thousands of years. There was no change in DIC weathering output from $\mathrm{C} 2$ since silicate weathering in this model does not increase the DIC flux to the ocean. Alkalinity flux from $\mathrm{C} 1$ exceeded that of other model versions towards the end of the simulation period as the slower carbon removal resulted in much warmer surface conditions (due to the longer residence time of carbon dioxide in the atmosphere) compared to other model versions.

The evolution of ocean sedimentation is presented in Fig. 8b using five model variables: ocean carbon, calcite buried mass, upward/downward flux of calcite, and pore layer portion. Ocean carbon levels remained similar between $\mathrm{C} 1$ and $\mathrm{C} 2$ during the first 2 thousand years, after which $\mathrm{C} 1$ overtook $\mathrm{C} 2$ and eventually $\mathrm{A} 0$, despite resulting in the least amount of carbon removal of the three model versions. This is because $\mathrm{C} 1$ would send as much DIC into the ocean as alkalinity, which is counterproductive to atmospheric carbon removal. Inversely, $\mathrm{C} 2$ removed almost as much carbon as A0 while adding $1000 \mathrm{Pg} \mathrm{C}$ less into the ocean, testifying to the efficiency of silicate weathering in removing carbon from the atmosphere compared to carbonate weathering. Calcite sedimentation followed a very similar evolution to the experiments in Group B (Sect. 3.2), with the calcite pore layer portion remaining unchanged for 1000 years until the upward flux of calcite (dissolution) became larger than the downward flux of calcite (production/precipitation). Here it becomes clear that rock weathering, and, in particular, silicate weathering, is crucial in maintaining the stability of the pore layer fraction in the long term. Model version C3, where weathering rates remain constant, produced a much 
(a)
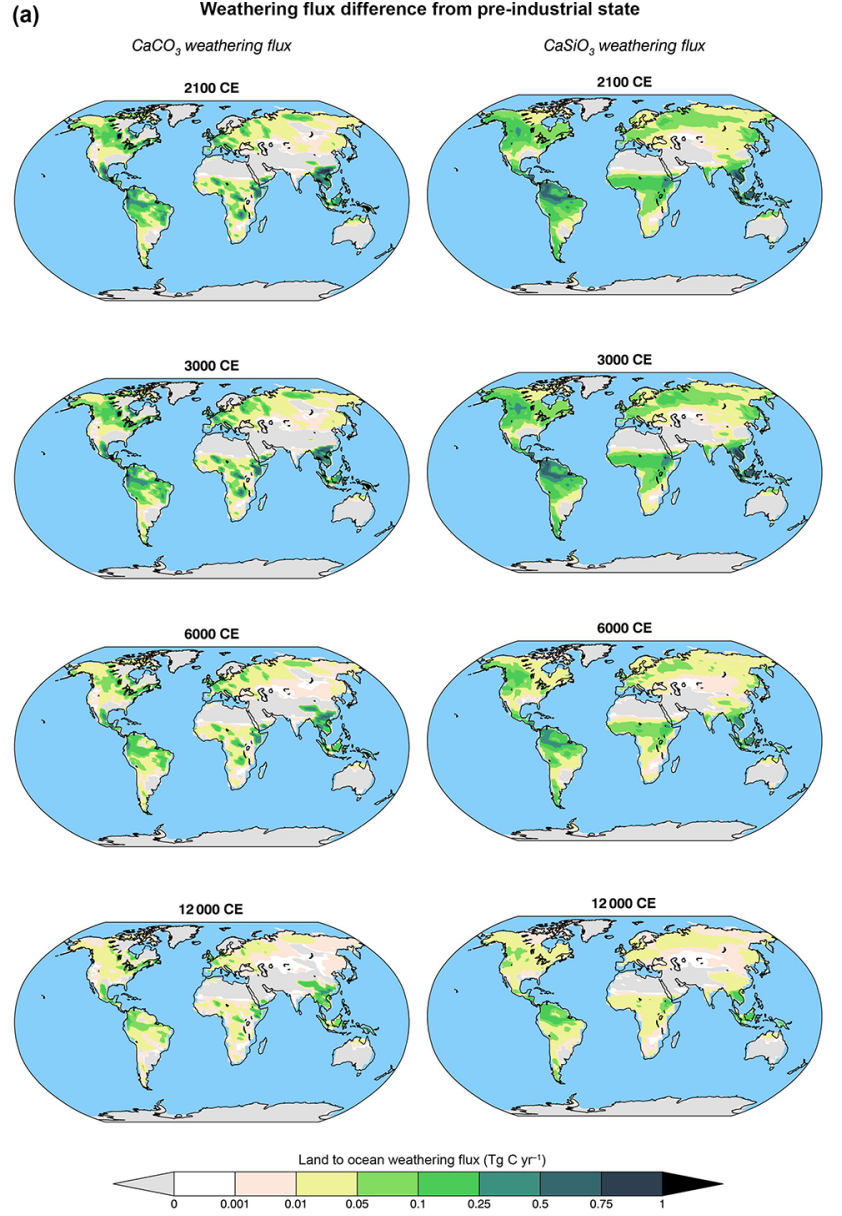

(b)
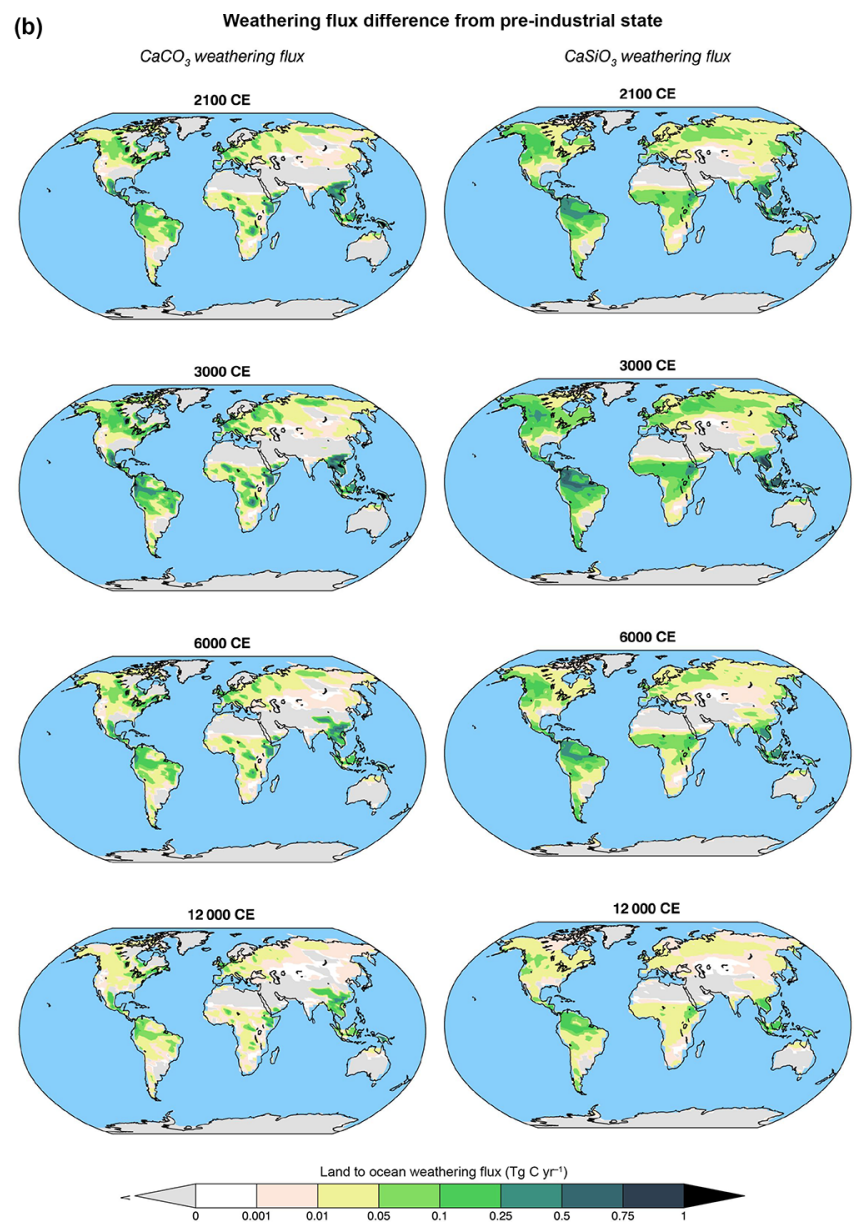

Figure 7. Spatial distribution of changes in carbonate $\left(\mathrm{CaCO}_{3}\right)$ and silicate $\left(\mathrm{CaSiO}_{3}\right)$ weathering changes for experiment $\mathrm{B} 1$ between preindustrial steady state (year $1800 \mathrm{CE}$ ) and years 2100, 3000, 6000, and $12000 \mathrm{CE}$. Note the nonlinear color scale, used to better display values during the later stages of the model simulation.

sharper increase in calcite dissolution compared to A0, where both weathering types respond to changes in climate, and the burial of $\mathrm{CaCO}_{3}$ in sediments occurred much faster in $\mathrm{A} 0$ than in $\mathrm{C} 3$. Additionally, pore layer portion was better maintained by silicate weathering $(\mathrm{C} 2)$ than carbonate weathering (C1). These results suggest that the alkalinity flux supplied by silicate weathering is necessary not only for decreasing the oceanic buffer factor (i.e., the concentration of carbonic acid and carbonate in ocean surface water) and allowing the uptake of more $\mathrm{CO}_{2}$ from the atmosphere but also to maintain a better balance of the oceanic sedimentary pore layer by mitigating the increase in calcite dissolution in the deep compared to the production rate in the surface layer.

\section{Discussion}

The weathering scheme introduced here is subject to some caveats relating to the formulation itself, as well as the limitations inherent in the UVic model. Colbourn et al. (2013) carefully discuss the potential misrepresentation of temper- ature as a factor, especially when other parameters such as vegetation productivity are also taken into account. In particular, it is possible that the temperature dependency for carbonate weathering (Eq. 7), which was developed empirically from correlating groundwater $\mathrm{CaCO}_{3}$ concentration with water temperature in various river catchment basins, also captures the coincident changes in vegetation productivity and river runoff, hence making the other factors redundant to a certain extent. Whether this would introduce a significant error to the modeling is questionable, as temperature on its own was shown to have at most a moderate impact on overall changes in weathering rates (see Sect. 3.1).

The validity of the other two parameterizations - NPP and runoff - is difficult to assess as the formulations are based on the arbitrary assumption that weathering rates vary monotonically with changes in the two parameters. The representation of the biological enhancement of weathering through changes in vegetation NPP is a daunting task indeed, and neither our understanding of the underlying processes nor the complexity of the UVic model terrestrial module would al- 

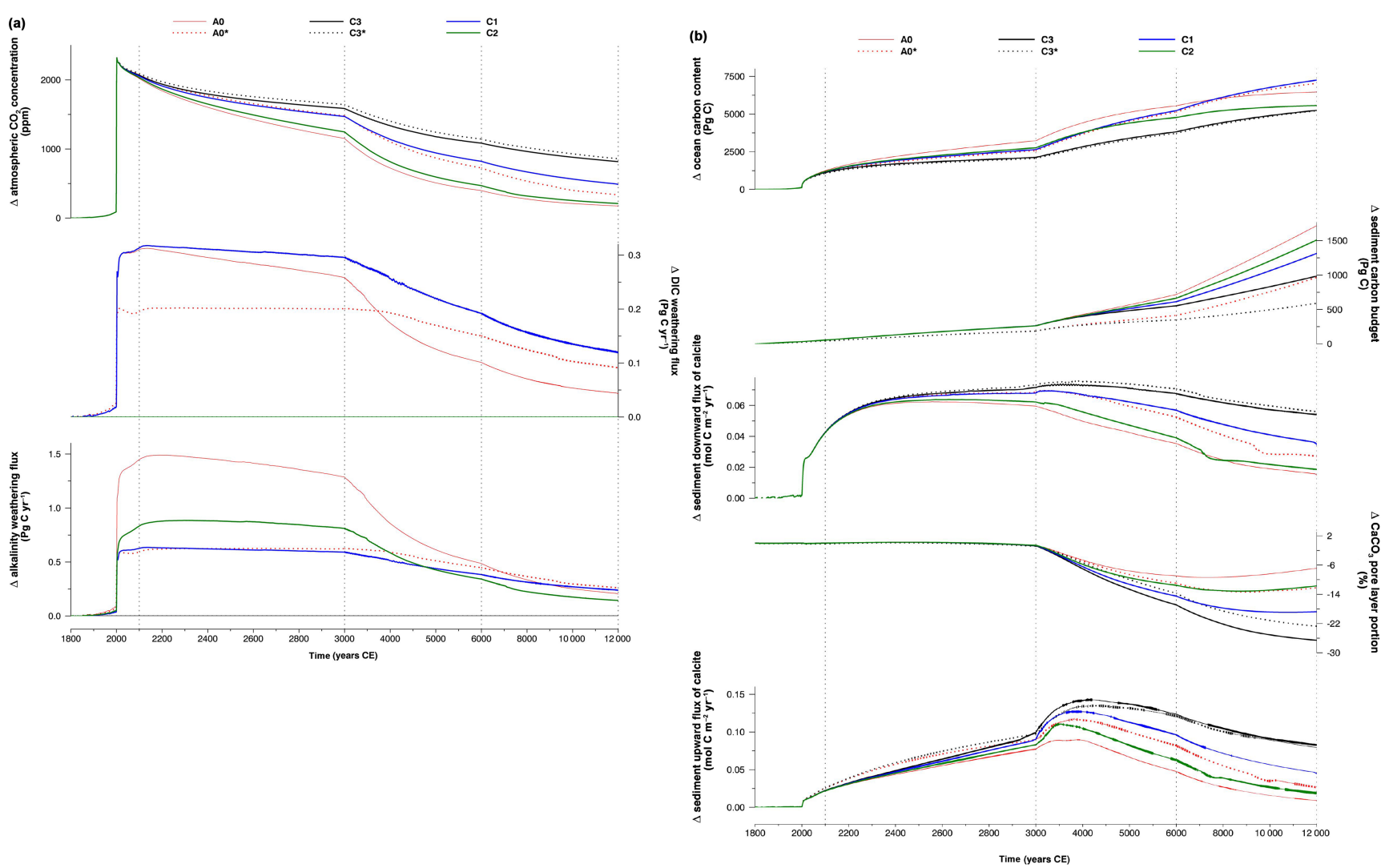

Figure 8. Time series of simulated changes in various model outputs for Group C scenarios, compared with pre-industrial steady-state values. These scenarios include A0 (both weathering types active), C1 (carbonate weathering only), C2 (silicate weathering only), and C3 (no weathering), as well as the zero-dimensional counterparts to C0 and C3 (indicated by the "**" symbol). Shown here are (from top to bottom) (a) atmospheric $\mathrm{CO}_{2}$ concentrations, and weathering fluxes of DIC and alkalinity; and (b) oceanic carbon difference, sediment carbon difference, downward flux of calcite into sediments, calcite pore layer portion, and dissolution of calcite in sediments. Note the different scales along the time axis, which change at years 3000 and 6000 . Vertical dashed lines are used to indicate times for which results are shown in Figs. 4, 5, and 7. The curves shown here represent experiments A0 (red), C1 (blue), C2 (green), and C3 (black), with dashed colored lines representing the zero-dimensional equivalent model version (when available).

low for a parameterization which accurately reflects the underlying mechanisms. For example, the parameterization is meant to represent the physical impacts of root expansion, and the chemical impacts of soil kinetics, on the breakdown of rock into minerals and their eventual dissociation by carbonic acid; therefore, an ideal productivity scheme would account for the impacts of various plant types on each of the lithologies in terms of areal coverage, root expansion, and other relevant quantities. It is difficult to assess the uncertainty related to the choice of NPP parameterization, as there is not an equivalent alternative formulation of the biological enhancement of weathering with which to gauge the validity of the results presented here - reverting to $\mathrm{CO}_{2}$ as the main proxy for biological activity would be arguably a worse choice than NPP.

Moreover, it should be noted that the efficiency both the NPP and runoff schemes in our model rely heavily on the initial (steady-state) ratio between weathering and NPP/runoff, meaning that a change in a parameter in an initially low- activity region (such as colder climates) may have a disproportionately higher impact on weathering rates compared to changes in tropical areas. It is possible that the introduction of vegetation in a previously nonvegetated area would introduce a stress likely to drastically increase rock erosion, but this is an effect that would be better represented by directly parameterizing the new plant type as a stress on the underlying lithology. For a better alternative, one could consider a weathering scheme based on the absolute value of NPP/runoff (using, for example, a nonlinear empirical function linking weathering rate and net primary productivity) rather than the ratio of the current value to the initial value. The development of such a relationship, however, would require a more in-depth investigation of the role of plants, and biotic activity in general, on the physical and chemical erosion of rocks.

Another source of uncertainty in our results lies in the UVic model itself. While very well suited to simulate longterm impacts of carbon emissions and increased weather- 
ing rates on ocean biogeochemistry, on a shorter timescale $\left(10^{2}-10^{3}\right.$ years) the lack of advanced atmospheric dynamics prevents the model from adapting to the extreme warming brought on by carbon emissions in a manner consistent with our understanding of global climate. Under extreme warming there is a poleward shift of the tropical and subtropical cells and consequent changes in precipitation patterns, leading to a potential overestimate of atmospheric temperature and moisture content changes over tropical regions (see Sect. 3.1). This effect is important mostly between years 2000 and $3000 \mathrm{CE}$ and fades away as the brunt of the climate and biogeochemical changes are shifted to the oceans. The model's simplified precipitation scheme also likely affects its ability to simulate runoff changes, which are central to both the initiation and modulation of weathering rates.

Terrestrial rock weathering is a complex mechanism with many variables worth considering, many of which have a high degree of interdependence (Walker et al., 1981; Berner, 1991; Lenton and Britton, 2006). In the scheme introduced in this paper for the UVic model, we considered the impacts of temperature, productivity and runoff (all parameters previously examined in zero-dimensional weathering models), along with lithological distribution to drive spatial variability. However, many other factors which affect weathering rates were unaccounted for that could also be relevant in the context of a spatially explicit weathering scheme. Perhaps the most meaningful of all is the consideration of sea level change. It is highly likely that the extreme warming caused by anthropogenic emissions would result in a significant melting of the Greenland and West Antarctic ice sheets (Clark et al., 2016), not only disrupting the freshwater balance in the polar oceans but also providing enough of a global rise in sea levels along with the thermal expansion of seawater to flood many coastal areas. Many of the low-elevation continental shelves threatened by sea level rise are situated in weathering active, tropical regions, and therefore the interruption of terrestrial weathering due to the flooding of these areas could have a more than trivial effect on global weathering output, thus weakening the response to global warming. Note that the extensive warming could also bring about a decrease in ice sheet area, especially in Greenland, which would open up some potentially very active weathering regions (Kump and Alley, 1994). However, the extent of this areal reduction of ice sheet cover over a few thousand years is likely to be overwhelmingly compensated for by the area of land flooded by sea level rise.

Another factor of some relevance is the interaction with land biogeochemistry. There has been an extensive discussion in recent years on the role of mid- to high-latitude peatlands in the context of a rapidly warming Earth, especially with regard to the decarbonation of these ecosystems and subsequent release of greenhouse gases in the atmosphere (mostly methane) that could greatly amplify global warming (Le Roux and Shotyk, 2006). While the release of methane by itself does not directly affect terrestrial weathering, there are a variety of soil processes within peatlands which are triggered or amplified by warming and which would have a significant local effect on the chemical dissociation of rocks.

There are many other factors which would be worth investigating, ranging from anywhere between the physical break down and grinding of rocks by roots to the chemical enhancement of weathering due to the presence of active reagents (Ridgwell and Zeebe, 2005). For example, a distinction between physical and chemical weathering would allow the inclusion of factors such as altitude, as wind and relief/slope play a major role in physical weathering. The impact of ground frost at higher latitudes also leads to erosion, and could increase weathering rates in colder climates. Finally, one cannot ignore anthropogenic impacts, in particular the spread of modern agriculture, in which crop yields are often boosted using mineral fertilizers and other chemicals, which mix in with the soil water and accelerate the erosion of the bedrock. Other features of the Anthropocene worth mentioning include acid rain and land use change, all of which need to be taken into consideration in order to better represent the modern dynamics of global biogeochemistry. Unfortunately, it is unlikely that most of these factors can be properly integrated in current low- and intermediate-complexity climate models, on account of their requiring a spatial resolution much finer than what most Earth system models of intermediate complexity can offer. For example, the UVic model's $1.8^{\circ} \times 3.6^{\circ}$ resolution cannot resolve physical mechanisms which occur over a single-kilometer spatial scale.

\section{Conclusions}

A spatially explicit weathering scheme has been developed and integrated into the University of Victoria Earth System Climate Model (UVic ESCM). The model was constructed in such a way that weathering rates at a certain point are computed based on the difference in temperature, vegetation net primary productivity, and runoff, between that point and pre-determined initial conditions. In our model, those initial conditions were based on pre-industrial runoff and lithology (Amiotte Suchet et al., 2003), which provides the basis for the two-dimensionality of the model.

The model was tested with scenarios of future climate change, using (in most cases) a pulse of $5000 \mathrm{PgC}$ at year 2000 to simulate climate system recovery from anthropogenic emissions and the role of global weathering during the following 10000 years. Overall, the model results suggested that weathering has a negligible effect on atmospheric $\mathrm{CO}_{2}$ and ocean biogeochemistry on short timescales, but its impact becomes more discernible as we progress to multimillennial timescales. We also found that climate system recovery from carbon emissions was much faster using a two-dimensional model rather than the zero-dimensional model versions used in previous work. Among the various climate factors used in the model, we found primary produc- 
tivity to be by far the most important, producing an increase in global weathering far higher than a model version using atmospheric $\mathrm{CO}_{2}$ levels to represent biotic activity, or one where only temperature and runoff changes were considered. This highlights the need for further research to determine whether this effect of biotic activity on physical and chemical weathering is in fact an important real-world process that is independent of temperature and/or runoff change. Lithology itself was also found to be very important, often meaning the difference between a weathering-active and high- and lowweathering region. In terms of global totals, carbonate weathering was found to be more prominent than silicate weathering, mostly on account of weathering-vulnerable rocks being mostly carbonate-weathered. However, our results clearly emphasized that silicate weathering is the only process of the two which has the capacity to fully restore the climate system to pre-industrial levels (on timescales of $10^{5}$ years), thus confirming the findings of Colbourn et al. (2013).

This work has established the importance of using a spatially explicit weathering scheme to better represent longterm changes in carbon biogeochemistry. Our approach, although crude, has demonstrated that weathering can be integrated on the grid-cell level and still produce reasonable results. This study did not take into account the more subtle aspects of spatial variability, such as the impacts of ice sheets, sea level changes, and local factors such as soil activity and topography. These are therefore important processes to include in further analyses of the effect of deglacial weathering changes on ocean biogeochemistry and climate change.

Data availability. The model code is property of University of Victoria and cannot be made public. All of the relevant data are presented in Figs. 1-8.

Competing interests. The authors declare that they have no conflict of interest.

Acknowledgements. We thank P. Amiotte Suchet for providing the dataset for the worldwide rock type distribution for the GEM-CO $\mathrm{CO}_{2}$ model, as well as $\mathrm{K}$. Meissner for providing the code for 0-D model versions, A. Mucci for helping us better understand carbonate chemistry, G. Colbourn for his assistance in understanding the RokGeM model, and two anonymous reviewers for their helpful comments. The support of NSERC Discovery Grants awarded to L. A. Mysak and H Damon Matthews is also gratefully acknowledged.

Edited by: G. Bala

Reviewed by: two anonymous referees

\section{References}

Amiotte Suchet, P. and Probst, J. L.: A global model for present day atmospheric/soil $\mathrm{CO}_{2}$ consumption by chemical erosion of continental rocks (GEM-CO 2 ), Tellus B, 47, 273-280, 1995.

Amiotte Suchet, P., Probst, J. L., and Ludwig, W.: Worldwide distribution of continental rock lithology: Implications for the atmospheric/soil $\mathrm{CO}_{2}$ uptake by continental weathering and alkalinity river transport to the oceans, Global Biogeochem. Cy., 17, 10381051, 2003.

Archer, D.: A data-driven model of the global calcite lysocline, Global Biogeochem. Cy., 10, 511-526, 1996.

Archer, D.: Fate of fossil fuel $\mathrm{CO}_{2}$ in geologic time, J. Geophys. Res.-Oceans, 110, 9-14, 2005.

Archer, D., Kheshgi, H., and Maier-Reimer, E.: Multiple timescales for neutralization of fossil fuel $\mathrm{CO}_{2}$, Geophys. Res. Lett., 24, 405-408, 1997.

Archer, D., Eby, M., Brovkin, V., Ridgwell, A., Cao, L., Mikolajewicz, U., Caldeira, K., Matsumoto, K., Munhoven, G., Montenegro, A., and Tokos, K.: Atmospheric lifetime of fossil fuel carbon dioxide, Annu. Rev. Earth Planet. Sc., 37, 117-134, 2009.

Bergman, N. M., Lenton, T. M., and Watson, A. J.: COPSE: A new model of biogeochemical cycling over phanerozoic time, Am. J. Sci., 304, 397-437, 2004.

Berner, R. A.: A model for atmospheric $\mathrm{CO}_{2}$ over Phanerozoic time, Am. J. Sci., 291, 339-376, 1991.

Berner, R. A.: GEOCARB II: A revised model of atmospheric $\mathrm{CO}_{2}$ over Phanerozoic time, Am. J. Sci., 294, 56-91, 1994.

Berner, R. A. and Kothavala, Z.: GEOCARB III: A revised model of atmospheric $\mathrm{CO}_{2}$ over Phanerozoic time, Am. J. Sci., 301, 182-204, 2001.

Berner, R. A., Lasaga, A. C., and Garrels, R. M.: The carbonatesilicate geochemical cycle and its effect on atmospheric carbon dioxide over the past 100 million years, Am. J. Sci., 283, 641683, 1983.

Bitz, C. M., Holland, M. M., Weaver, A. J., and Eby, M.: Simulation the ice-thickness distribution in a coupled climate model, J. Geophys. Res., 106, 2441-2463, 2001.

Bluth, G. J. S. and Kump, L. R.: Lithologic and climatologic controls of river chemistry, Geochim Cosmochim. Ac., 58, 23412359, 1994.

Brady, P. V.: The effect of silicate weathering on global temperature and atmospheric $\mathrm{CO}_{2}$, J. Geophys. Res., 96, 18101-18106, 1991

Cao, L., Bala, G., Caldeira, K., Nemani, R. and Ban-Weiss, G.: Importance of carbon dioxide physiological forcing to future climate change, P. Natl. Acad. Sci. USA, 107, 9513-9518, 2010.

Clark, P. U., Shakun, J. D., Marcott, S. A., Mix, A. C., Eby, M., Kulp, S., Levermann, A., Milne, G. A., Pfister, P. L., Santer, B. D., Schrag, D. P., Solomon, S., Stocker, T. F., Strauss, B. H., Weaver, A. J., Winkelmann, R., Archer, D., Bard, E., Goldner, A., Lambeck, K., Pierrehumbert, R. T., and Plattner, G.-K.: Consequences of twenty-first-century policy for multi-millennial climate and sea-level change, Nature Climate Change, 6, 360-369, https://doi.org/10.1038/nclimate2923, 2016.

Colbourn, G., Ridgwell, A., and Lenton, T. M.: The Rock Geochemical Model (RokGeM) v0.9, Geosci. Model Dev., 6, 1543-1573, https://doi.org/10.5194/gmd-6-1543-2013, 2013.

Cox, P.: Description of the "TRIFFID" Dynamic Global Vegetation Model, Met Office, Hadley Centre technical note 24, 2001. 
Cox, P., Betts, M., Bunton, R. A., Essery, C. B., Rowntree, R. L., and Smith, J.: The impact of new land surface physics on the GCM simulation of climate and climate sentisivity, Clim. Dynam., 15, 183-203, 1999.

Donnadieu, Y., Goddéris, Y., and Bouttes, N.: Exploring the climatic impact of the continental vegetation on the Mezosoic atmospheric $\mathrm{CO}_{2}$ and climate history, Clim. Past, 5, 85-96, https://doi.org/10.5194/cp-5-85-2009, 2009.

Ebelmen, J. J.: Sur les produits de la décomposition des espèces minérales de la famille des silicates, Ann. Mines, 7, 3-66, 1845.

Eby, M., Zickfeld, K., Montenegro, A., Archer, D., Meissner, K. J., and Weaver, A. J.: Lifetime of anthropogenic climate change: Millennial time scales of potential $\mathrm{CO}_{2}$ and surface temperature perturbations, J. Climate, 22, 2501-2511, 2009.

Ewen, T. L., Weaver, A. J., and Eby, M.: Sensitivity of the inorganic ocean carbon cycle to future climate warming in the UVic coupled model, Atmos. Ocean, 42, 23-42, 2004.

Fanning, A. F. and Weaver, A. J.: An atmospheric energy-moisture balance model: climatology, interpentadal climate change and coupling to an ocean general circulation model, J. Geophys. Res, 128, 15111-15128, 1996.

Gibbs, M. T. and Kump, L. R.: Global chemical erosion during the last glacial maximum and the present: Sensitivity to changes in lithology and hydrology, Paleoceanography, 9, 529-543, 1994.

Gibbs, M. T., Bluth, G. J. S., Fawcett, P. J., and Kump, L. R.: Global chemical erosion over the last $250 \mathrm{Myr}$; variations due to changes in paleogeography, paleoclimate, and paleogeology, Am. J. Sci., 299, 611-651, 1999.

Harmon, R. S., White, W. B., Drake, J. J., and Hess, J. W.: Regional hydrochemistry of North American carbonate terrains, Water Resour. Res., 11, 963-967, 1975.

Indermühle, A., Stocket, T. F., Joos., F., Fischer, H., Smith, H., Wahlen, M., Deck, B., Mastroianni, D., Tschumi, J., Blunier, T., Meyer, R., and Stauffer, B.: Holocene carbon-cycle dynamics based on $\mathrm{CO}_{2}$ trapped in ice at Taylor Dome, Antarctica, Nature, 398, 121-126, 1999.

Kalnay, E., Kanamitsu, M., Kistler, R., Collins, W., Deaven, D., Gandin, L., Iredell, M., Saha, S., White, G., Woollen, J., Zhu, Y., Leetmaa, A., Reynolds, R., Chelliah, M., Ebisuzaki, W., Higgins, W., Janowiak, J., Mo, K. C., Ropelewski, C., Wang, J., Jenne, R., and Joseph, D.: The NCEP/NCAR 40-year reanalysis project, B. Am. Meteorol. Soc., 77, 437-471, 1996.

Kump, L. R. and Alley, R. B.: Global chemical weathering on glacial time scales, P. o. National Research Council, Material Fluxes on the Surface of the Earth, 46-60, 1994.

Lenton, T. M. and Britton, C.: Enhanced carbonate and silicate weathering accelerates recovery from fossil fuel $\mathrm{CO}_{2}$ perturbations, Global Biogeochem. Cy., 20, GB3009, https://doi.org/10.1029/2005GB002678, 2006.

Le Roux, G. and Shotyk, W.: Weathering of inorganic matter in bogs, Developments in Earth Surface Processes, 9, 197-215, 2006.

Matthews, H. D. and Caldeira, K.: Stabilizing climate requires near-zero emissions, Geophys. Res. Lett., 35, L04705, https://doi.org/10.1029/2007GL032388, 2008.

Matthews, H. D., Weaver, A. J., and Meissner, K. J.: Terrestrial carbon cycle dynamics under recent and future climate change, J. Climate, 18, 1609-1628, 2005.
Matthews, H. D., Eby, M., Ewen, T., Friedlingstein, P., and Hawkins, B. J.: What determines the magnitude of carbon cycle-climate feedbacks?, Global Biogeochem. Cy., 21, GB2012, https://doi.org/10.1029/2006GB002733, 2007.

Meissner, K. J., Weaver, A. J., Matthews, H. D., and Cox, P.: The role of land surface dynamics in glacial inception: A study with the UVic Earth System Climate Model, Clim. Dynam., 21, 515537, 2003.

Meissner, K. J., McNeil, B. I., Eby, M., and Wiebe, E. C.: The importance of the terrestrial weathering feedback for multimillennial coral reef habitat recovery, Global Biogeochem. Cy., 26 , GB3017, https://doi.org/10.1029/2011GB004098, 2012.

Meybeck, M.: Global chemical weathering of surficial rocks estimated from river dissolved loads, Am. J. Sci., 287, 401-428, 1987.

Montenegro, A., Brovkin, V., Eby, M., Archer, D., and Weaver, A. J.: Long term fate of anthropogenic carbon, Geophys. Res. Lett., 34, 19707-19711, 2007.

Moon, S., Chamberlain, C. P., and Hilley, G. E.: New estimates of silicate weathering rates and their uncertainties in global rivers, Geochim. Cosmochim. Ac., 134, 257-274, 2014.

Nugent, K. A. and Matthews, H. D.: Drivers of future northern latitude runoff change, Atmos. Ocean, 50, 197-206, 2012.

Pacanowski, R. C.: MOM 2 documentation, user's guide and reference manual, Princeton, GFDL Ocean Group Technical Report, NOAA, GFDL, 232 pp., 1995.

Peltier, W. R.: Global glacial isostasy and the surface of the iceage Earth: The ICE-5G (VM2) Model and GRACE, Annu. Rev. Earth. Planet. Sc., 32, 111-149, 2004.

Ridgwell, A. and Hargreaves, J. C.: Regulation of atmospheric $\mathrm{CO}_{2}$ by deep-sea sediments in an Earth system model, Global Biogeochem. Cy., 21, GB2008, https://doi.org/10.1029/2006GB002764, 2007.

Ridgwell, A. and Zeebe, R.: The role of the global carbonate cycle in the regulation and evolution of the Earth system, Earth Planet. Sc. Lett., 234, 299-315, 2005.

Sarmiento, J. and Gruber, N.: Ocean Biogeochemical Dynamics, Princeton University Press, Princeton, 2006.

Schartau, M. and Oschlies, A.: Simultaneous data-based optimization of a 1d-ecosystem model at three locations in the North Atlantic: I. Mothod and parameter estimates, J. Mar. Res., 61, 765793, 2003.

Schmittner, A., Oschlies, A., Matthews, H. D., and Galbraith, E. D.: Future changes in climate, ocean circulation, ecosystems, and biogeochemical cycling simulated for a business-as-usual $\mathrm{CO}_{2}$ emission scenario until year $4000 \mathrm{AD}$, Global Biogeochem. Cy., 22, GB1013, https://doi.org/10.1029/2007GB002953, 2008.

Sundquist, E.: Steady- and non-steady-state carbonate-silicate controls on atmospheric $\mathrm{CO}_{2}$, Quaternary Sci. Rev., 10, 283-296, 1991.

Uchikawa, J. and Zeebe, R. E.: Influence of terrestrial weathering on ocean acidification and the next glacial inception, Geophys. Res. Lett., 35, L23608, https://doi.org/10.1029/2008GL035963, 2008.

Urey, H. C.: The planets: their origin and development, Yale University Press, New Haven, Conn, 1952. 
Walker, J. C. and Kasting, J. F.: Effects of fuel and forest conservation on future levels of atmospheric carbon dioxide, Palaeogeogr. Palaeocl., 97, 151-189, 1992.

Walker, J. C., Hays, P. B., and Kasting, J. F.: A negative feedback mechanism for the long-term stabilization of Earth's surface temperature, J. Geophys. Res., 86, 9776-9782, 1981.
Weaver, A. J., Eby, M., Wiebe, E. C., Bitz, C. M., Duffy, P. B., Ewen, T. L., Fanning, A. F., Holland, M. M., MacFadyen, A., Damon Matthews, H., Meissner, K. J., Saenko, O., Schmittner, A., Wang, H., and Yoshimori, M.: The UVic Earth System Climate Model: model description, climatology, and applications to past, present and future climates, Atmos. Ocean, 39, 361-428, 2001. 